\title{
LOS PRIMEROS INSTRUMENTOS MUSICALES PRECOLOMBINOS: LA FLAUTA DE PAN ANDINA O LA "ANTARA"
}

\author{
CARLOS D. SÁNCHEZ HUARINGA \\ UNIVERSIDAD NACIONAL MAYOR DE SAN MARCoS \\ karlos_202@hotmail.com
}

Hay tanta música en el mundo que es razonable suponer que la música como el lenguaje y posiblemente la religión, es un rasgo específico de nuestra especie. (Balcking 1973, 2006)

\section{RESUMEN}

La música en el Perú prehispánico, como en toda sociedad, está basada principalmente en la necesaria invención y uso de los instrumentos musicales. En nuestro caso, sabemos que las flautas de pan, cuáles sean estas: antaras, sikus, zampoñas, etc., han sido los principales artefactos sonoros que han dado vida a la música andina. En el presente documento indagamos los primeros vestigios arqueológicos de las flautas de Pan considerando otros aerófonos andinos de manera adyacente.

Palabras claVe: Música, aerófonos, flautas de pan, antaras, siku, zampoñas.

\begin{abstract}
The music in the pre-Hispanic Peru, as in any society, is based primarily on the necessary invention and use of musical instruments. In our case, we know the panpipes, which are these: antaras, sikus, panpipes, etc., were the main sonic artifacts that have given life to Andean music. In this paper we investigate the first archaeological remains of the panpipes considering other Andean wind instruments adjacently.
\end{abstract}

KEYWORDS: Music, aerophones, pan flutes, panpipes, siku, panpipes. 


\section{INTRODUCCIÓN}

\section{MÚSICA E INSTRUMENTOS MUSICALES PRECOLOMBINOS}

La música ha sido parte intrínseca de la formación y desarrollo de las sociedades y culturas andinas y es como en todas las sociedades del mundo, el espacio inmaterial espiritual que refleja o expresa la vida material, la realidad y sus imaginarios o las mentalidades colectivas (cosmovisión), por ello su importancia: "Encontramos en la música una síntesis de los procesos cognoscitivos propios de una cultura y, también, del resultado de sus interacciones sociales (...) La música es un producto del comportamiento de los grupos humanos, ya sea formal o informal: es sonido humanamente organizado." (Blacking 1973: 25).

Por lo tanto, todo investigador del tema supone que la música (canto, voz e instrumentos musicales) fue tan importante y estuvo tan presente en la vida social y sus acontecimientos principales tanto en el ámbito personal (nacimiento, casamiento, muerte y demás ritos de pasajes), como en lo social (familiares, económicas, políticas, ideológicas, militares, agrícolas, religiosas, médicas y demás). También habría estado presente y de manera diferenciada para cada ocasión, de acuerdo al tipo, nivel, poder y prestigio de su gente (como hasta ahora); y se tendría de hecho una música especial con instrumentos o artefactos sonoros pensados para cada momento y lugar que la cosmovisión indicaba.

Pero a la vez, sabemos que la música es una construcción y expresión abstracta cuyo carácter temporal (fugaz, de existencia momentánea) hace que sea imposible su perpetuación sin la existencia de medios como la escritura musical o las grabadoras de sonido ${ }^{1}$. Vale decir que la música del antiguo Perú se ha perdido para siempre, pero gracias a que esta se materializó vía la invención de los "artefactos sonoros" (como los instrumentos musicales) y estos en su mayoría son aparatos tangibles, han podido sobrevivir al paso del tiempo permitiéndonos no sólo un mayor acercamiento, sino, alguna posibilidad de remisión a ese mundo inmaterial desconocido².

Sin embargo, tenemos que decir que pese a la innegable importancia de la música y sus instrumentos para el análisis de las sociedades antiguas, la arqueología no ha sido muy cuidadosa en el registro y estudio de las evidencias musicales y la rama de la arqueo musicología es una motivación muy última y en nuestro caso peruano aún incipiente. Con mucho asombro hemos observado lo común que es el desconocimiento de los arqueólogos respecto de los artefactos sonoros e instrumentos musicales, algunos escandalosamente desorientados como para asustarnos por el tipo de lectura que podrían hacer en sus descubrimientos arqueológicos o por su simple omisión. Sin duda, mucha información debe haberse perdido por acción de los "huaqueros" y el desconocimiento arqueológico:

1.- Recién a mitades del siglo XIX se inventaría los primeros equipos de grabación de sonidos. El antecedente más remoto aconteció en 1857 cuando León Scott patentó el fonoautógrafo, este artefacto es considerado el primero en registrar sonidos en un medio visible...

2.- Distinguimos "artefactos sonoros" e "instrumentos musicales": el primero nos ayuda a un mayor agrupamiento de muchos artefactos que emiten sonidos y que no necesariamente son o pueden ser instrumentos musicales propiamente, mientras que el segundo si se refiere exactamente a aquellos artefactos sonoros que han sido inventado y utilizados con la finalidad de hacer música sean estos sean estos melódicos o no. Música a la vez, desde una perspectiva antropológica, la definimos como la combinación de sonidos con sentido o comprensión social producidos mayormente por artefactos sonoros. O como diría Blacking (1973), se trata de "sonidos humanamente organizados". 
En la arqueología, un instrumento musical, es lo único vivo que llega a nosotros. Fuera de él no hay otra cosa que reaccione a nuestros requerimientos. Todo lo demás es cosa muerta que no puede más que acumular sobre sí incógnitas, teorías contradictorias y divagaciones. Y siendo un instrumento musical lo único vivo, lo único utilizable que nos ha llegado hay una actitud de inmadurez de nuestros investigadores arqueólogos (...) Los instrumentos musicales arqueológicos constituyen la fuente primordial para el esclarecimiento de los principales aspectos culturales de las épocas que ellos proceden. (Castro Franco 1961).

Aun así, la arqueología peruana ha realizado importantes descubrimientos de artefactos sonoros e instrumentos musicales que nos permiten una gran aproximación al mundo de la "música andina prehispánica" y al que en esta oportunidad, nos acercaremos vía el estudio de estos aerófonos que han sobrevivido a la catástrofe del tiempo y de los huaqueros.

De acuerdo a la clasificación más utilizada en la música, de Sachs-Hornbostel (1914), los instrumentos musicales se dividen en cuatro órdenes principales: cordófonos, aerófonos, idiófonos y membranófonos ${ }^{3}$. De estos, el mundo andino no conoció la orden de los cordófonos, en cambio los aerófonos (flautas de todo tipo) y los membranófonos (instrumentos de percusión) fueron la base de la antigua música originaria prehispánica y muy especialmente formaron parte de la vida musical -inclusive hasta nuestros días- de estos. Tres tipos de instrumentos musicales forman la base del mapa sonoro andino: los bombos, las zampoñas y las quenas (denominaciones comunes). Veamos un poco más sobre estos:

Membranófonos.- Los llamados comúnmente "bombos" o "tambores", pertenecen a esta orden puesto que emiten sonidos por acción del golpe de las membranas (cueros de animales) que poseen ${ }^{4}$. Los membranófonos son inventados tempranamente por las sociedades pre hispánicas y muchas variantes de estas llegan hasta nuestros días como las cajas (denominados así en la sierra norte), las tinyas (sierra centro) y las wankaras (sierra sur). Arqueológicamente podemos

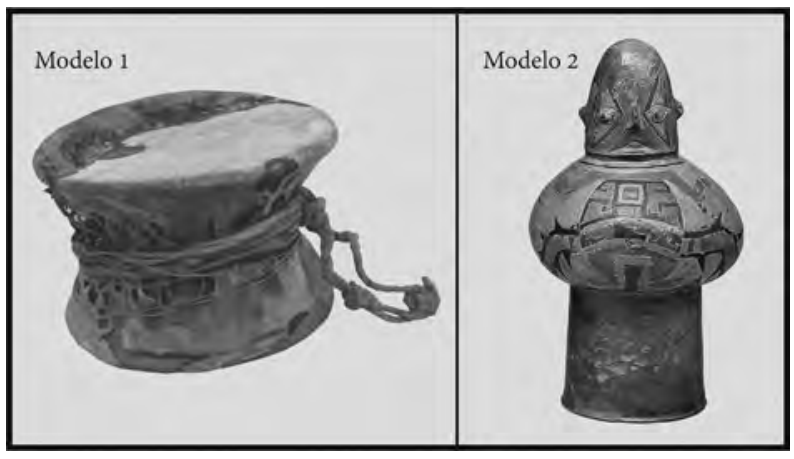
distinguir dos importantes modelos: 1) Cilíndrico de doble membrana o "bi cóncavo" (culturas Vicus, Wari, Lima, Moche y Chimú, entre los principales y que llega en alguna medida hasta la actualidad) y cuyo material de construcción del cuerpo o estructura varía entre la cerámica rústica, la madera y los carrizos. 2) Cónico de una membrana (Paracas, Nazca y Chiribaya), en cuyo caso los materiales de construcción del cuerpo ha sido únicamente la cerámica. Se trata de un modelo que se extingue para el tiempo Inca.

3.- En la clasificación tradicional de instrumentos de Sachs-Hornbostel hallamos cuatro grupos principales: cordófonos, aerófonos, idiófonos y membranófonos, pero últimamente se le ha añadido el grupo de los electrófonos. En nuestro caso andino, todos los tipos de "bombos" (como las wankaras y las tinyas) pertenecen al grupo de los membranófonos mientras que todos los tipos de "quenas" (pinkullos, tarkas, etc.) y los tipos de "zampoñas" (sikus, antaras, etc.) pertenecen al grupo de los aerófonos y también tenemos idófonos andinos como las shacshash y diversas sonajas.

4.- Se dice que en los tiempos antiguos, se usaban membranas de seres humanos, posiblemente de enemigos condenados a muerte. 
Idiófonos.- Junto a los diferentes tipos de "bombos", en el mundo andino prehispánico tenemos el uso de los idiófonos; aquellos artefactos que producen sonido por la vibración, golpe o rozamiento entre materiales en contacto. Los principales serán las sonajas (de distintas formas y material de construcción) y las shacshash, fabricada

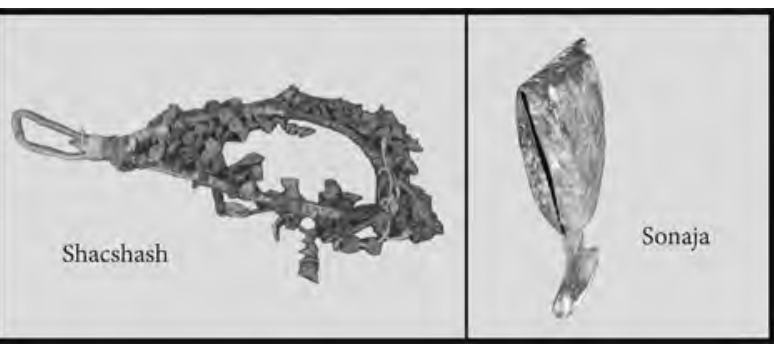
principalmente de semillas secas o de otros materiales (como los caracoles) y que con el rozamiento generan un especial sonido. También en este grupo podemos citar a los posibles litófonos (piedras que emiten sonido al ser golpeados), bastante inusual en el caso peruano.

Aerófonos.- Sin duda, nuestras antiguas y actuales sociedades son consideradas el mayor asiento de los aerófonos a nivel planetario. El mundo andino prehispánico muestra una gran variedad de aerófonos, entre ellos las trompetas, las huaylla quepas (pututos), los silbatos, las ocarinas, las flautas globulares y las botellas silbadoras. Pero emerge con mucha presencia el uso de un tipo de aerófonos llamado flautas en sus dos principales modelos o tipos: 1) las flautas de ducto (tipos "quenas") y 2) Las flautas de pan (tipo "zampoñas"). Estas últimas son las que más nos han llamado la atención por la gran variedad y simbología que encierra, además de su furtivo uso. En la actualidad tenemos dos modelos muy característicos de flautas de pan y que devienen del tiempo pre hispánico: las antaras y los sikus. ${ }^{5}$

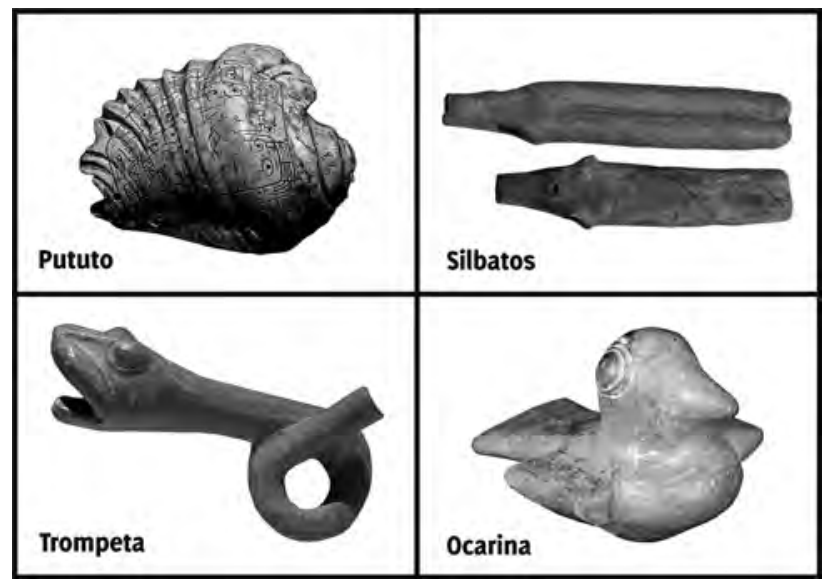

Tengamos en cuenta que no todo artefacto sonoro era o es un instrumento musical, muchas veces algunos de estos (sólo) cumplen funciones sociales específicas. De tal manera que posiblemente el huaylla quepa (pututo) habría sido utilizado específicamente para rituales religiosos (como debemos suponer en el caso de Chavín), también para emitir códigos o mensajes vía la diversidad de sonoridades (convocatorias, alertas y otros tipos de mensajes), como fue en el caso del tiempo del incanato. Igual los silbatos como las trompetas, es posible que tuvieran un uso no musical. Mientras los que consideramos propiamente instrumentos musicales como las flautas y los artefactos de percusión (bombos) es posible que además de usarse como instrumento musicales, participaban

5.- No discutimos aquí si los artefactos sonoros muy conocidos y usados como los "pututos", las "trompetas", los silbatos y las "botellas silbadoras" son o no instrumentos musicales, o si los sonidos emitidos por estos eran considerados "música" o formaban parte de esta. 
también de otras esferas y momentos por el tipo de sonoridad que podían emitir, como los momentos de sanación (como hasta ahora), en las guerras, y principalmente de conexión con los espacios divinos (rituales mágicos religiosos).

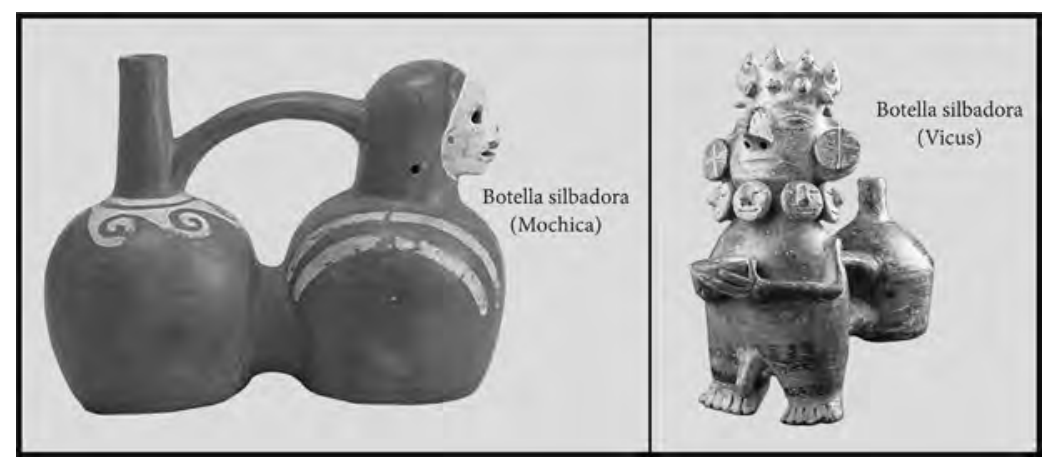

Las "botellas silbadoras" han existido desde culturas tempranas (como Vicus) en el caso peruano al parecer influenciadas desde culturas norteñas (ecuatorianas como Chorrera). Es sin duda un "artefacto sonoro" pero muy difícil considerarlo un "instrumento musical". 6

\section{La flauta de pan andina: definición}

El objetivo de este trabajo es escudriñar sobre cuáles serían o son los artefactos sonoros e instrumentos musicales más antiguos haciendo un especial énfasis en los aerófonos andinos más emblemáticos de nuestro mundo originario: las flautas de Pan (sean estos antaras, sikus u otros) ${ }^{7}$ :

La flauta de Pan (421.112 en la clasificación de Hornbostel \& Sachs) es un aerófono o instrumento de viento compuesto por un número variable de tubos (o, en ciertos casos conductos) de distintas longitudes $y$ grosores, generalmente cerrados por un extremo y abiertos o semi-abiertos por el otro. En su extremo proximal, tales tubos pueden ser lisos o poseer biseles simples o dobles; dependiendo de tamaños $y$ cumpliendo los principios acústicos que rigen el sonido de este tipo de elementos (Fletcher 2005), los distintos tubos que componen el aerófono proporcionan diferentes notas y, mediante el empleo de ciertos recursos interpretativos, una serie de variables de armónicos. (Civallero 2012: 40).

Decimos o creemos que las flautas de pan (llamados también "antaras") son los instrumentos musicales más emblemáticos en esta etapa de la civilización andina, en primera instancia porque se trata de uno de los artefactos sonoros que viene desde los primeros asientos humanos en nuestro territorio (Caral por ejemplo). En segundo lugar, debido a la multiplicidad de formas y variedades que hasta hoy sobreviven haciendo conocido a Sudamérica como el asiento de las flautas de Pan a nivel del mundo. Además encierra simbologías muy significativas como la dualidad (la "flauta de pan dual complementaria") derivado del esquema dualista del mundo andino y el uso de la "hilera secundaria" otra importante propiedad de la flauta de pan andina que correspondería a una peculiar estética sonora andina.

6.- Para un mayor acercamiento a la temática de las "botellas silbadoras" ver: José Pérez de Arce "Análisis de las cualidades sonoras de las botellas silbadoras prehispánicas de los Andes”. Boletín del Museo Chileno de Arte Precolombino, № 09, 2004.

7.- El término "flauta de Pan" viene del dios griego Pan: “(En griego "todo") era el semidiós de los pastores y rebaños en la mitología griega (...) Era cazador, curandero y músico. Habitaba en los bosques y en las selvas, correteando tras las ovejas y espantando a los hombres que penetraban en sus terrenos. Portaba en la mano el cayado o bastón de pastor y tocaba la Siringa, a la que también se conoce como Flauta de Pan (...) En la Grecia antigua, se conocía este instrumento con el nombre de siringa en honor a la náyade Siringa (Sýrinx), una ninfa que el dios Pan trató de violar y fue convertida en caña. También se la conoce como flauta de Pan." En: http://es.wikipedia.org/ 
A pesar del avance de la ciencia arqueológica y la tecnología, es aun imposible afirmar el contexto (tiempo y espacio) en el que aparece la flauta de Pan en nuestro territorio. Sin embargo, debido a su "simpleza" en su forma organológica y su sencilla ejecución de inicio; podemos inferir que este artefacto estuvo junto al hombre andino prácticamente desde sus inicios civilizatorios, acompañándolo luego en sus complejidades socio culturales hasta la actualidad. Las principales variantes de las flautas de pan en nuestro territorio actualmente son las antaras y los sikus, pero evidentemente sus orígenes vienen desde los tiempos precolombinos.

\section{LA FLAUTA DE PAN Y LA ANTARA: PRECISIONES TERMINOLÓGICAS}

La arqueología peruana, desde tiempos de las primeras excavaciones dirigidas por Julio C. Tello (inicios del siglo XX), ha hecho común el uso del término "antara" para designar a estos instrumentos musicales precolombinos. Sin embargo, existe una evidente arbitrariedad en cuanto a este uso pues el término "antara" es quechua y la sociedad Nazca obviamente no lo fue. Américo Valencia nos dice: “... instrumentos arqueológicos que, en sus libretas de campo (Julio C. Tello), denominó antaras, a pesar de que la cultura Nazca que se desarrolló en el periodo Intermedio Temprano, no tiene relación directa con la cultura e idioma quechua." (Valencia 2007: 303). Desde entonces, la arqueología peruana utilizó y aún utiliza el término "antara" como genérico para denominar a todas las flautas de Pan arqueológicas, sin prestar atención o investigar sobre las especificidades o particularidades de este aerófono (como sus nombres mismos) en el período prehispánico, peculiaridades por cierto muy complejas aún hoy para la arqueo musicología.

¿Pero de donde viene el término antara? "Antara” es recogido por los cronistas españoles a su llegada a estas tierras. Aparece en el Vocabulario de la lengua general de todo el Perú de González Holguín de 1608, donde dice: “Antara. Flautillas juntas como órgano”. El cronista Bernabé Cobo (1653) también lo menciona: "Antara es otro género de flauta corta y ancha", diferenciándola claramente del ayarichic (que sería el actual siku y que en algunos casos sigue siendo llamado ayarachi). También la "antara” es mencionado en reiteradas ocasiones por Guamán Poma de Ayala en su voluminosa obra Nueva corónica i buen gobierno (1615) (1936): “Cómo tenía los Yngas y capac apo tanbores grandes con que se holgauan y le llamauan poma tinya y tronpeta guaylla quepa, pototo, flautas pingollo, antara, pipo, cata vari, varoro, quena quena...” (p. 336). Francisco de Ávila (Cusco, 1573 - Lima, 1647) en sus escritos muy conocidos bajo el nombre de Dioses y hombres de Huarochirí, que fueron traducidos al castellano por José María Arguedas (1966), menciona en varias oportunidades a la "antara" como un instrumento principal de la mitología andina: "... el raposo traería una flauta hechas de muchas cañas que los indios llaman antara..." (p. 211). Hay otra importante cantidad de testimonios hispánicos sobre este instrumento llamado "antara" (voz quechua) por las poblaciones que ellos contactaron. Se trataba entonces de un tipo de instrumento musical, aerófono del tipo flauta de pan situado geográficamente hacia el norte del Tawantinsuyo diferenciándose claramente del "ayarichi" (luego siku) otra variedad de flauta de pan situada hacia el altiplanicie andina, al sur del Tawantinsuyo.

A partir de estas tradiciones léxicas, la arqueología peruana que inicia su trabajo formal a inicios del siglo XX, utiliza esta denominación para designar a las flautas de pan descubiertos en sus excavaciones. Nosotros procuramos no usar este término toda vez que se arriesga a confusión entre las antaras arqueológicas y las antaras etnográficas ya que en la actualidad hay una gran vigencia de flautas de pan denominadas "antaras" y otras que no lo son, como los sikus altiplánicos. Por ello para el presente artículo usaremos mayormente la denominación genérica y académica de flautas de Pan, de lo contrario encomillaremos el término "antara", por ser como ya dijimos, muy arbitrario su uso. 
sin embargo, en el caso peruano existe toda una tradición arqueológica de llamar "antara" a todas las flautas de pan halladas en las excavaciones arqueológicas. La distinción entre antara y siku o zampoña será muy determinante pero ya en el caso etnográfico actual, mas no para la etapa pre hispánica.

Ubicaremos la existencia y características de las primeras flautas de Pan precolombinas en el Perú tratando de relacionar las cronologías más usadas hasta ahora y propuestas por Luis Lumbreras y John Rowe; la cronología procesual y la estilística.

\section{I}

\section{PERIODO ARCAICO / PRE CERÁMICO}

\section{(APROX. 7,000 - 2,000 A.C.)}

En el inicio de este periodo, estudiado por arqueólogos de mucho reconocimiento como Max Uhle, Julio C. Tello y Frederic Engel, tenemos el desarrollo de poblados como Paloma, Santo Domingo (en Paracas), Telarmachay, Guitarrero, Tres Ventanas, Piquimachay, El Encanto, La Yerba, Chilca, Caral y otros. En especial tenemos el asentamiento de Santo Domingo de Paracas (6800 a.C.), donde se dice que se habría hallado el primer instrumento musical: una flauta. Esta versión la encontraremos en algunos libros y más aún en el internet, pero todas desgraciadamente obvian las fuentes y otras pruebas que serían de mucha utilidad por la aseveración que expresan. Según el musicólogo Carlos Mansilla (2009), por estas afirmaciones, se terminó construyendo un "rumor" en el medio académico que casi de manera mecánica usaban (usan) este dato, dato que Mansilla la desmintió de manera categórica en su artículo: "El artefacto sonoro más antiguo del Perú: aclaración de un dato histórico". Disertación y afirmación que apoyamos pues hemos estado cerca de los datos manejados por este autor.

\section{LA “QuenA" DE ChilCA, el PRIMER instrumento musical PREColombino}

El arqueólogo suizo Frederic Engel centra sus estudios arqueológicos en la "aldea Chilca", ubicado a 70 kilómetros al sur de Lima próxima a la costa. En ellas busca encontrar y estudiar los vestigios de los primeros momentos de la vida neolítica y los inicios del sedentarismo en nuestro territorio. Los restos hallados y estudiados por él se sitúan a lo largo de periodo Arcaico, desde sus inicios (Arcaico Inicial 7000 a.C.) en las pampas de Santo Domingo de Paracas y hasta los finales del mismo, el Arcaico Tardío (que llega hasta los 2000 a.C.). Su centro de atención, sin duda fue Chilca al que el carbono 14 le dio una antigüedad aproximada de 5700 (+/- 136 años), es decir unos 3750 a.C.: "Los habitantes de "Pueblo 1" vivieron en chozas de forma circular con paredes hechas de junco, caña o esteras, soportadas por ramas o cañas gruesas. Al interior, el piso estaba excavado a unos 40 centímetros de la superficie. El diámetro promedio, para las chozas, es de 2.50 metros. Sobre el piso, una delgada cobertura de restos de conchas, plantas y otros materiales orgánicos.” (Engel 1988: 12).

Engel publica en 1988 el libro "Ecología Prehistórica Andina", en ella sale a la luz los productos y piezas de sus trabajos de excavación en Chilca, vestigios de esta aldea del periodo Arcaico (pre cerámico o de los horticultores semi nómades). En los restos de chozas semi subterráneas de planta

8.- En este artículo Mansilla rebate la datación (casi tradicional) sobre el instrumento más antiguo hallado en el Perú, dice "El presente artículo se trata precisamente sobre el artefacto sonoro más antiguo hallado hasta hoy en el Perú y de la imprecisión de su datación real (...) esta datación fue formulada inicialmente por el arqueólogo Jorge Silva, quien asignaba la edad aproximada de 7000 a.C. a unas flautas halladas en Chilca por Frederic Engel..." La misma que termina corrigiendo pues de acuerdo a su propia leyenda esta se trataría de: "Flauta de madera decorada con motivos pirograbados. El tema es un mono tocando flauta. Edad: 5750 años. Pueblo 1 de Chilca". 
circular, halló entierros humanos e indicios de actividades económicas como la pesca, recolección y horticultura, con una antigüedad aproximada de 3750 a.C. En uno de los entierros de un hombre de 35 años en promedio, halló una flauta de ducto, es decir un instrumento musical "tipo quena" de cuatro agujeros para su digitación y hecho en madera (Figura 1). Este evidentemente instrumento musical, uno de los más antiguos que ha descubierto la arqueología peruana:

Tumba de un adulto de unos 35 años de edad; media como $1.51 \mathrm{~m}$. de estatura. Estaba echado en sentido noroeste-sureste, la cabeza al noroeste, los brazos extendidos. El cadáver había sido envuelto en una estera amarrado con soguillas sobre la cabeza y alrededor de los pies. El fardo contenía una flauta tipo quena, es decir un trozo de caña con cuatro agujeros decorada con el motivo pirograbado de una animal de pie tocando la flauta. Además se encontraron un palillo de madera y una espina de huarango. El tórax había sido perforado, clavando el cadáver al suelo con una aguja de hueso con agujero. (Engel 1988: 28)

Por otro lado, el musicólogo Carlos Mansilla Vásquez hacia el año 2009 en el artículo ya citado, corroborará que en la aldea de Chilca había sido hallado "El artefacto sonoro arqueológico más antiguo identificado hasta la fecha en el Perú, es una quena de madera hallada en el Pueblo 1 de Chilca, con una datación histórica de $5750 \pm$ años antes del presente (3,750 a.C.)" (Mansilla 2009: 192). Esta flauta vertical de un sólo tubo (una pequeña "quena" de aproximadamente $20 \mathrm{~cm}$ de largo) se encuentra en exhibición en el museo del CIZA (Centro de Investigaciones de Zonas Áridas de la Universidad Nacional Agraria La Molina), ahora MUNABA (Museo Nacional de Antropología, Biodiversidad, Agricultura y Alimentación), en la vitrina correspondiente a la "Época Agrícola Incipiente", con el siguiente texto como leyenda: "Este instrumento musical de aire, uno de los más antiguos encontrados en América, está construido en madera de caña y decorado con la técnica de pirograbado, en donde se representa a un personaje de pie tocando la flauta. Las dimensiones de la quena son de $230 \mathrm{~mm}$ de largo con $17 \mathrm{~mm}$ de diámetro y tiene aproximadamente 5750 años de antigüedad." (Museo Antropológico de la UNALM).

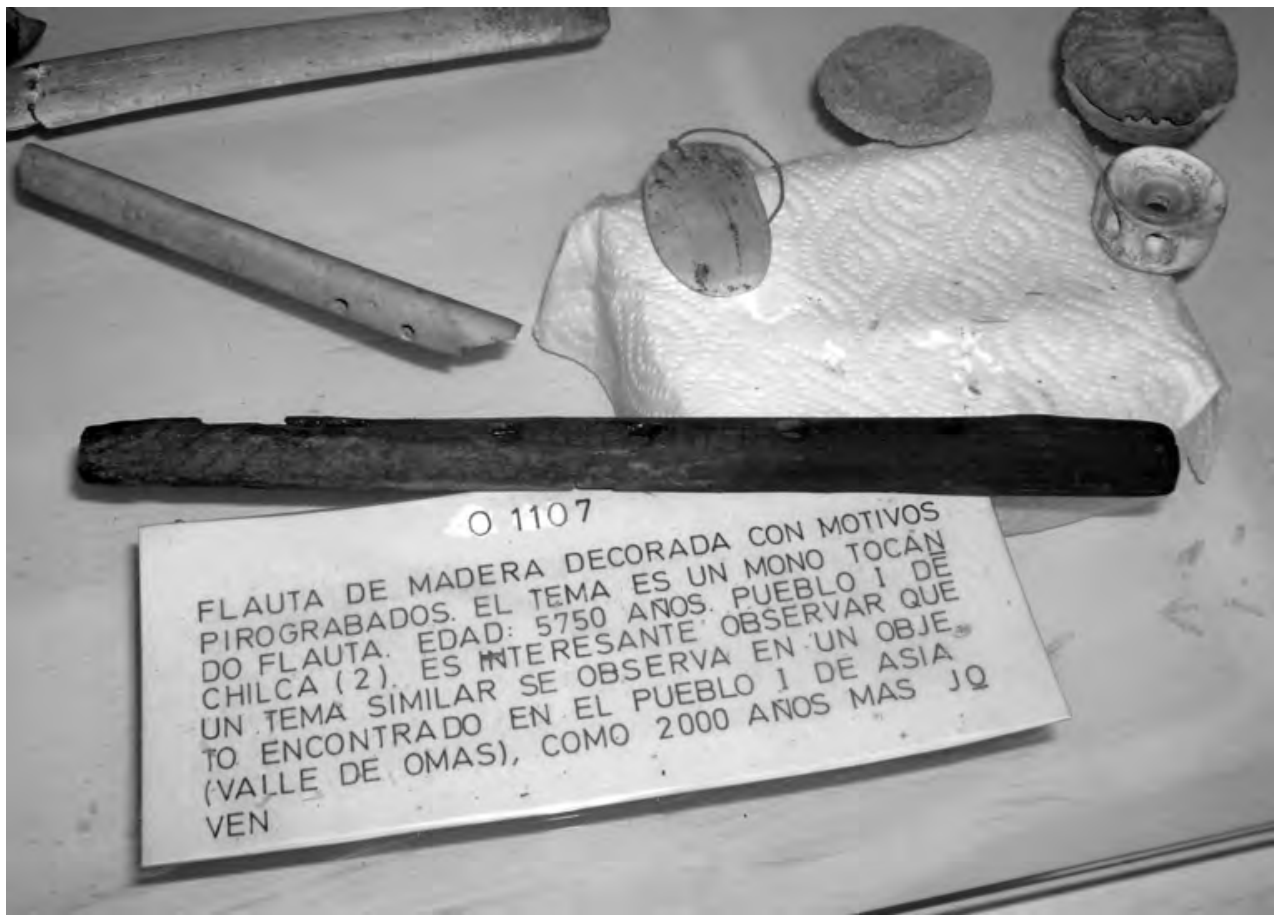

Figura 1: Flauta "quena" chilca, considerada el instrumento musical más antiguo que la arqueología peruana haya descubierto (aldea Chilca, Pueblo 1 con 3750 a.C.) 
Ciertamente, no hemos hallado en nuestro recorrido académico, siempre buscando los instrumentos "más antiguos", otro con mayor antigüedad. Si hemos encontrado en la misma publicación de Engel (p. 81, 91), una flauta de ducto de digitación horizontal ("tipo flauta traversa" de Caral) de huesos de ave, que fue considerada por Engel como "silbato" y que tiene aproximadamente la misma antigüedad (Figura 9).

\section{LA “ANTARA” DE Chilca: ¿LA PRIMERA FlaUta DE PAN?}

Nuevamente, en algunas publicaciones serias y más aún en páginas del internet, se dice que en la "aldea Chilca" se habría encontrado una "antara" de huesos que tendría unos 7000, 6000 o 4000 años de antigüedad: "Nuestra antara no es menos antigua que la de los griegos; existen evidencias de que hace 7000 años conocían en Chilca, al sur de Lima, cómo fabricar una siringa de caña..." (Bolaños 1988: 17). Otro autor nos dice: "La flauta de pan más antigua hasta ahora encontrada en el Perú la ubicamos en Chilca, 4000 a.C." (Uribe 1997: 278); una página de internet señala: "El hombre de Paracas o de Santo Domingo (6800 a.C.) es (también) considerado el primer músico del Perú” (Wikipedia) ${ }^{9}$. Versiones que lamentablemente tenemos que desmentir.

Esta "antara chilca" se encuentra también publicado en el libro de Federico Engel ya citado ("Ecología Prehistórica Andina" de 1988), en la Parte II, bajo el título de "Implementos de hueso de la colección CIZA" (p. 108). De ahí hemos extraído la imagen (Figura 2). Por la imagen podemos decir que se trata de una flauta de Pan de seis tubos y nada más, pues no existe mayores detalles de ella salvo lo que pueda haber en las complejas tablas adjuntas al inicio de cada parte del libro cuya lectura necesita de especialistas en la materia (la imagen publicada tampoco tiene escala, así que las dimensiones que mostramos la obtuvimos en una revisión personal a la "antara" pero cuyas imágenes recientes no podemos aún publicar).

En el museo del MUNABA se encuentran depositados (y en algunos casos exhibidos) la mayor parte de los descubrimientos de Federico Engel y ahí tuvimos conversaciones personales con la Sra. Gloria Villarreal Silva quien fuera asistenta de Engel a lo largo de su estadía en Lima y en la actualidad es administradora de las propiedades del MUNABA. Ella nos comentó que entre los bienes del museo no figuraba ninguna antara proveniente de la aldea de Chilca del Periodo Pre-cerámico, menos aún el museo cuenta con algún instrumento musical que provenga del hombre de Paracas (de Santo Domingo de Paracas, de inicios del Arcaico Temprano, es decir con una antigüedad de 7000 años). ¿Esta "antara" se debió haber extraviado? Pues no. La profesora Gloria revisando los archivos del MUNABA con mucha dedicación nos indicó contundentemente que la imagen que se encuentra en el libro de Engel se trataba de una "antara de clara procedencia y estilo Paracas". Si bien su procedencia es del sector de Chilca donde el arqueólogo Engel concentró sus excavaciones, se trataba de un periodo posterior al primer asentamiento en Chilca. Felizmente, como ya señalamos, tuvimos acceso a esta flauta de pan por lo que las dimensiones obtenidas las mostramos en detalles en la figura 4.

Regresando al libro en mención de Engel y en largas conversaciones con la Sra. Gloria, observamos que esta tiene claramente dos partes: La primera que trata sobre sus descubrimientos en Chilca (llamado "Chilca, Pueblo I") y la segunda sobre una colección de artefactos de huesos (llamado "Implementos de hueso de la colección CIZA"). En la primera se encuentra la "quena" y en la segunda la "antara". Realizamos una búsqueda de mayores datos de esta última en el libro y encontramos que Engel denomina Pueblo 14a al Pueblo de la Pampa de Paracas y esta es la leyenda que figura en el libro

9.- https://es.wikipedia.org/wiki/Periodo_Arcaico_Andino 
(además dice porvenir de la tumba 27), no existiendo más información. Es posible que los autores que mencionaron una "antara" de unos 7000 a.C. hallado por Engel en Chilca, hayan confundido a la sociedad o cultura Paracas (Formativo Medio, 500 a.C.) con el hombre de Paracas o de Santo Domingo (Arcaico Inicial, 7000 a.C.).

Pero además el libro genera otra posible confusión: al buscar los datos sobre la tumba 27 en los cuadros que se encuentra en la primera parte del libro, nos da como resultado que esta "antara" tendría una fecha de entre 2450 - 2550 a.C. No fuimos los únicos que llegamos a esa conclusión pues llevamos el libro de referencia para que sea revisado por arqueólogos del Museo de Arqueología y Antropología de la Universidad Nacional Mayor de San Marcos (UNMSM), quienes nos manifestaron que la "antara" en mención, encontrada y publicada por Engel, contaba con una antigüedad aproximada de 2500 a.C. (de acuerdo a las intrincadas tablas del libro). También nos indicaron que no existía mayor explicación sobre ella. Esta aseveración fue desechada por el Museo del MUNABA categóricamente al hacernos dos puntuales observaciones: 1) Las referencias de los materiales de la segunda parte del libro, no pueden ser analizadas con los cuadros de la primera (y así lo habían hecho los especialistas y nosotros también). 2) En la segunda parte del libro se considera materiales de la colección del CIZA de otros periodos y lugares no necesariamente provenientes de Chilca como si es el caso de la primera parte del libro.

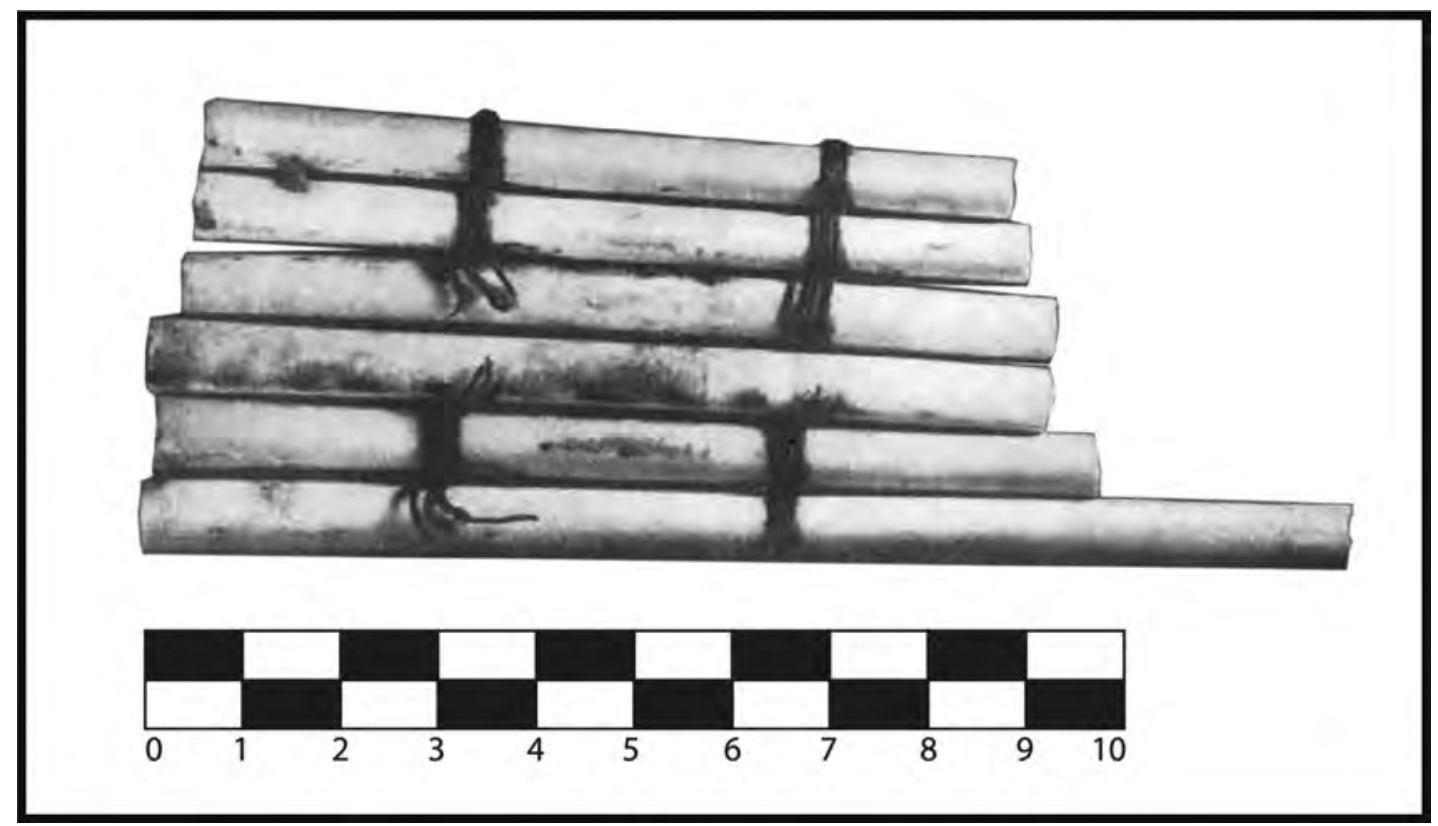

Figura 2: "Antara" hecho con huesos de pelícano encontrada por Federico Engel en la aldea Chilca (Lima). Su procedencia es de la sociedad Paracas y por lo tanto su antigüedad no más allá del Periodo Formativo.

Por otro lado, dimos con una flauta de Pan de huesos perteneciente a la cultura Paracas del Período Necrópolis, registrada por Julio C. Tello en sus primeros hallazgos, que, desgraciadamente, no tiene mayores detalles (Figura 3a). Fue una verdadera sorpresa la gran similitud entre esta flauta de pan y la hallada por Engel (Figura 3b), comparemos las dos imágenes. Además coincide con la versión de la es- 
pecialista del museo del MUNABA que nos señala que si bien esta “antara” había sido hallada por Engel en Chilca, pertenecería al periodo Paracas, pues el lugar fue reutilizado por pobladores de posteriores tiempos. En la figura 3c además presentamos a otra flauta de pan perteneciente a la cultura Paracas y que se encuentra en el Museo Nacional de Arqueología, Antropología e Historia del Perú (MNAAHP) y finalmente en la figura 3d incluimos una flauta de pan del Museo de Arqueología de la UNMSM que desgraciadamente no tiene contexto pero todo nos hace suponer que forma parte de las piezas pertenecientes a la cultura Paracas. Todas estas imágenes, como podemos observar tienen patrones en común repetitivos: Material de confección (huesos de aves o de animales pequeños), tamaño de las antaras (todos en promedio de $10 \mathrm{cms}$.) y forma de confección y amarres.

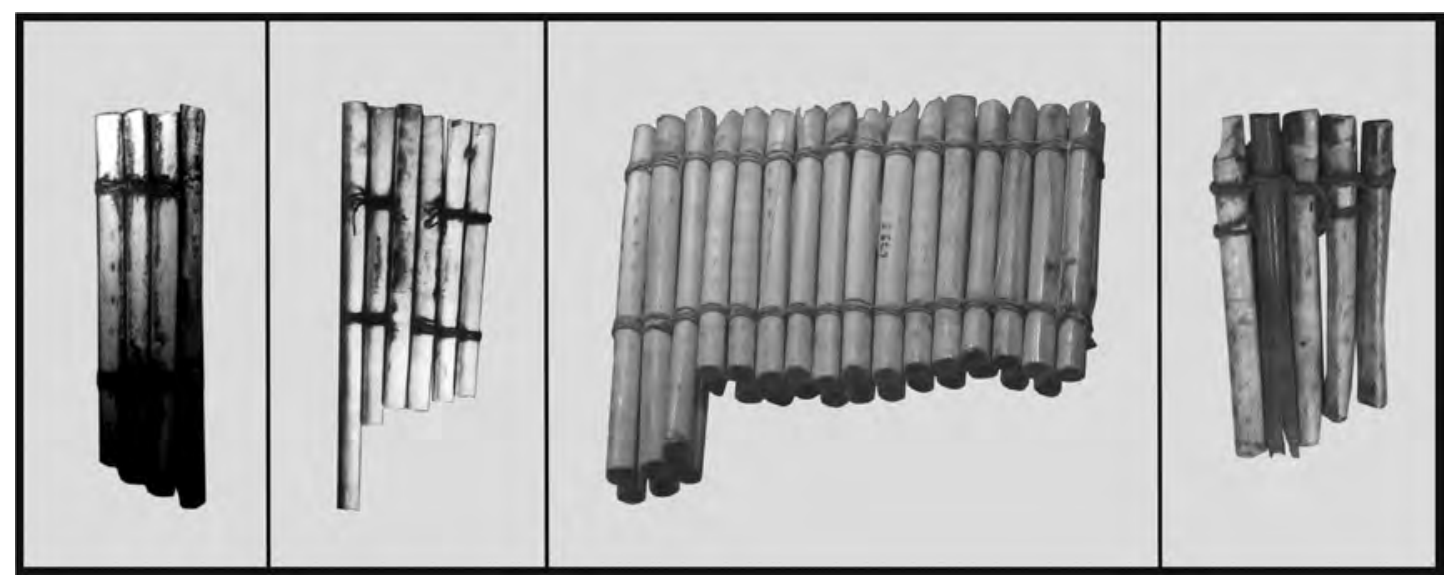

Figura 3: (3a) Flauta de Pan de Paracas construida de huesos de pelícano hallada por Julio C. Tello. ${ }^{10}(3 b)$ Flauta de pan de Paracas (6725/MNAAHP), (3c) Flauta de pan de Paracas proveniente de Chilca ya mencionada (MUNABA), (3d) Flauta de pan de posible origen Paracas (MAASM).

Finalmente, estas largas reuniones nos sirvieron para puntualizar que la flauta de pan (también llamada "antara" por Engel) fue hallada en una tumba en Chilca pero perteneciente al Periodo Formativo, claramente del tiempo y de la sociedad Paracas (quiere decir entre los 700 o 500 a.C. a unos 100 a.C.). Fue hallada en una tumba masculina sin mayores "privilegios", podemos decir en una relación de música y pueblo, o músico del pueblo al igual que la "quena" hallada unos tres mil años antes que esta "antara". Considerando las dimensiones que tiene, se trata de una flauta de pan "pequeña" (el tubo mayor tiene $12.3 \mathrm{cms}$. por $1 / 2 \mathrm{~cm}$. de diámetro), se distingue claramente un trabajo muy fino en su elaboración. Está hecha de huesos de ave (muy posiblemente de pelícano) y tiene desgaste en los bordes que nos expresan que fue utilizada y habría generado un sonido muy agudo por las dimensiones internas de los tubos. En su construcción se distingue el conocimiento de la acústica y el uso de tapones para los tubos de tal manera que se consiguió el sonido deseado por cada tubo. En la figura 4 dejamos señalado todas las dimensiones de esta flauta de pan que tanto ha sido mencionado por investigadores dedicado a la música primigenia señalándola como la más antigua de nuestro territorio.

10.- Sitio web: http://eca.state.gov/files/bureau/icpp/1peru/sect15.htm 

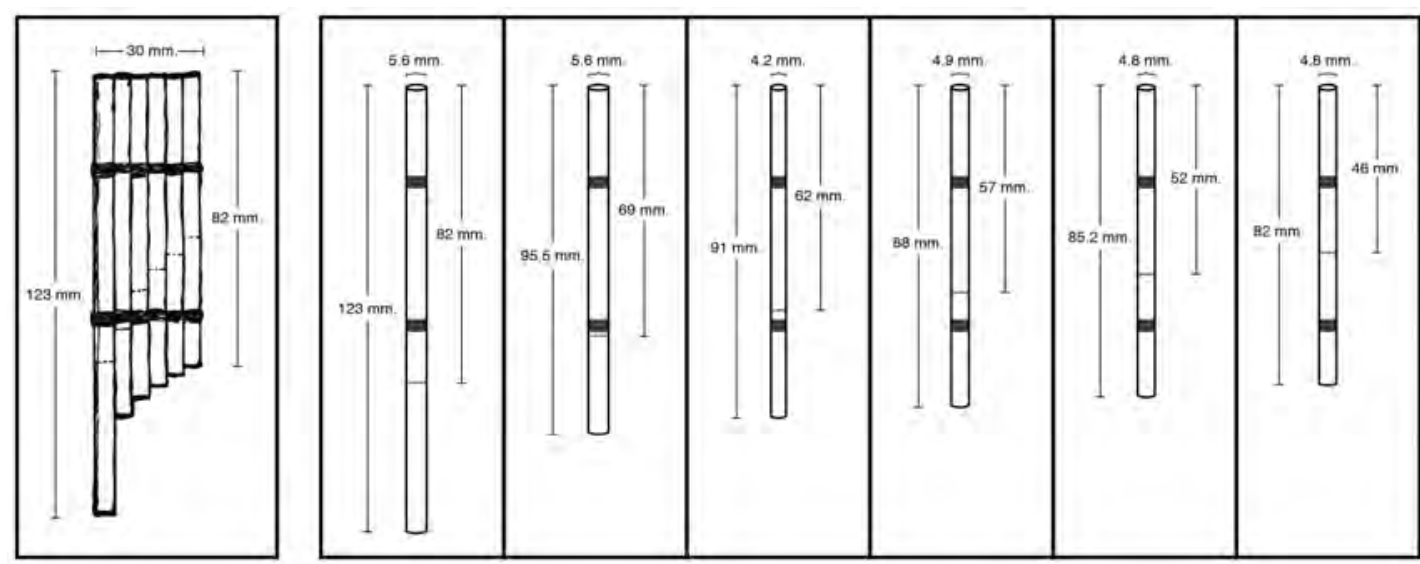

Figura 4: La flauta de Pan o "antara" Paracas (700 a.C.), se supuso por mucho tiempo que pertenecía a la aldea y al hombre de Chilca y que -por tanto- tenía una antigüedad aproximada de 5000 años de antigüedad, nunca podría provenir de los 7000 o 4000 a.C. pues no es la edad del hombre de Chilca. Presentamos aquí sus medidas detalladamente: largo externo y diámetro de los tubos que la componen y el largo interno que es el punto responsable de la altura del sonido.

\section{LA SOCIEDAD CARAL-SUPE}

En el Periodo del Arcaico Tardío, aun en el Pre cerámico, encontramos poblaciones como Cerro Paloma (Chilca), Huaca Prieta (La Libertad), Ventarrón (Lambayeque), Sechin Bajo en el valle de Casma y la Galgada (Ancash), Asia (Lima), Kotosh (en Huánuco) y otros menores. También tenemos la presencia de poblaciones como Miraya, Lurihuasi, Pueblo Nuevo, Allpacoto, Era de Pando, El Molino, Piedra Parada, Áspero (en el valle de Supe) y Vichama (en el valle de Huaura); todos en la zona nor-central del Perú.

El asentamiento humano de Caral también fue antes investigado y denominado Chupacigarro por Federico Engel, pero con la arqueóloga Ruth Shady se abrió un nuevo período para esta sociedad por la dedicada labor de excavación y estudio. Allí, hace unos años fue descubierto un impresionante grupo de instrumentos musicales: flautas de Pan (al parecer tres "antaras"), flautas de ducto tipo "traveseras" (un grupo de 32 flautas), un conjunto de 38 posibles "cornetas" hechas con hueso de camélido o venado, sin embocadura sobre el tubo y cuya superficie fue decorada con canales horizontales y una flauta tipo "quena". El asentamiento prehispánico de Caral, llamada por su mayor estudiosa "La civilización más antigua del territorio peruano" (Shady 2002), ${ }^{11}$ se encuentra también en la costa norte del departamento de Lima, en el distrito de Supe y provincia de Barranca y pertenece al periodo Pre cerámico y Arcaico Tardío (4000 - 2000 a.C.). Si bien se sitúa en la costa, el centro de la sociedad Caral se encuentra alejada del mar. Ruth Shady dice sobre esta:

11.- “...la Ciudad Sagrada de Caral fue edificada por el primer Estado político que se formó en el Perú 4400 años antes que gobernaran los Incas. Caral-Supe representa a la civilización más antigua de América, desarrollada casi simultáneamente con las de Mesopotamia, Egipto, India y China. Los habitantes del Perú se adelantaron en, por lo menos, 1500 años a los de Mesoamérica, el otro foco civilizatorio de los seis reconocidos mundialmente, y en más de 3000 años a la sociedad que edificó las reconocidas ciudades Mayas”. En: http://www.caralperu.gob.pe/ 
Los restos de la ciudad sagrada de Caral, datan de hace 3500 años, perteneciendo al período arcaico tardío. Por tanto es dos milenios (2000 años) anterior a Chavín de Huántar, siendo por tanto la más antigua y también el Estado más antiguo del Perú. Esta antigüedad, sitúa a la ciudad sagrada de Caral al tiempo de las ciudades sumerias de Mesopotamia o cuando se construían las pirámides de Keops en Egipto. Y en América sería lo más antiguo, porque recién hacia el 1,500 a.C., es que empiezan en Mesoamérica los asentamientos permanentes. En cambio en el Perú, estamos hablando de 2,500 a.C., casi un milenio antes. ${ }^{12}$

\section{LAS flautas "Traversas" De Caral}

En esta sociedad fueron hallados 32 instrumentos musicales, aerófonos tipo "quenas traveseras", exactamente definidos como "flautas tubulares horizontales o traversas" (Figura 5). ${ }^{13}$ Estas fueron construidas de huesos de pelícano (Pelecanus thagus) y cuyas medidas aproximadas serían de $10 \mathrm{cms}$ (unas más largas que las otras en no más de un centímetro) y de diámetro un promedio de $2 \mathrm{cms}$. que es la medida que fija el hueso del pelícano que se utiliza. Tiene un único orificio de embocadura de forma ovalada (en un par de casos son rectangulares) en el centro de la flauta. Todas tienen grabados o incisiones con motivos zoomorfos, se distingue muy claramente las figuras de monos, caras humanas, aves y reptiles. También se encontraron flautas sin decoración: "En el fondo de la embocadura un triángulo hecho de arcilla cruda sirve de tabique regulador que distribuye el aire entrante hacia ambos extremos. Fueron elaboradas usando huesos de ala de pelícano, cubito para las más delgadas y cortas y húmero para las más grandes y anchas." (Shady, Leyva y otros 2003).

Se calcula su antigüedad en aproximadamente 2500 a.C. y de acuerdo a las hipótesis de los investigadores del Proyecto Caral, estos estuvieron relacionados a rituales mágico-religiosos y también formaron parte de actividades sociales: “... fueron depositadas como ofrendas bajo el piso de la plaza circular en la Pirámide del Anfiteatro colocadas sobre una piedra cortada acompañadas por un canto rodado a un lado y al otro por una figurina humana de barro crudo sin rostro que se deshacía al tacto, todo cubierto por más piedras cortadas." (Shady 2004).

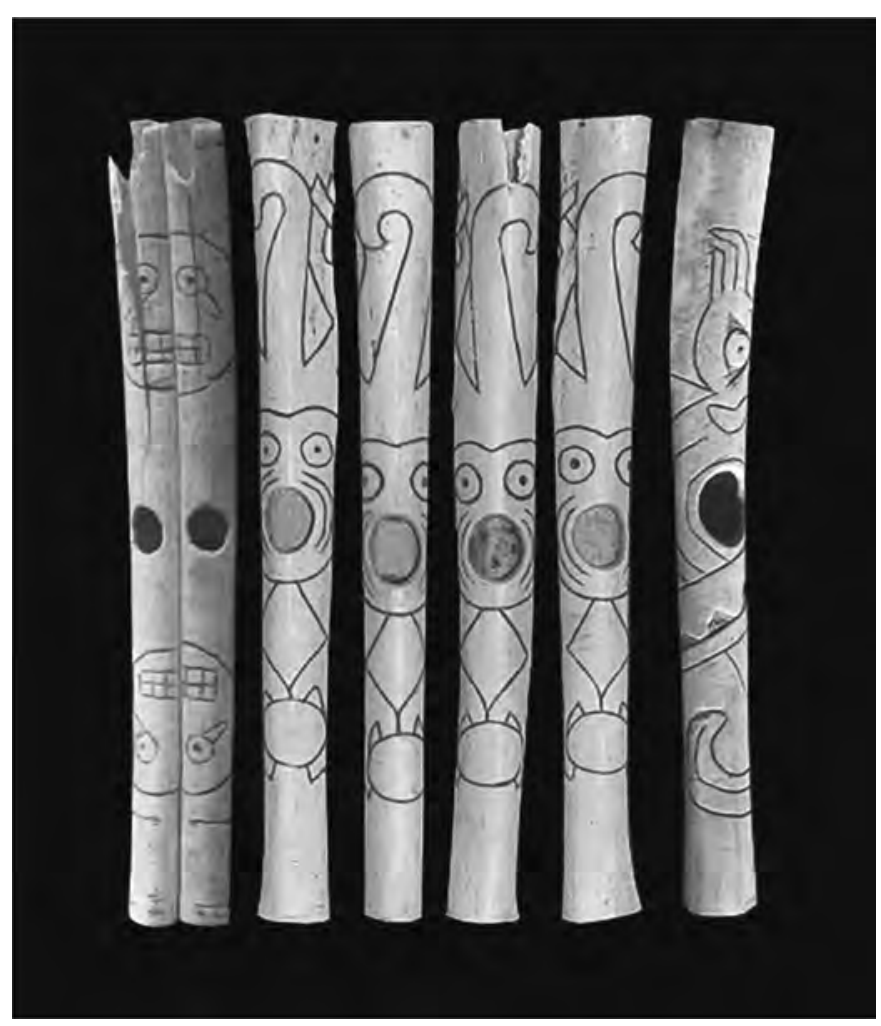

Figura 5: Las flautas de Caral, son evidentemente instrumentos musicales y por la cantidad encontrada (32 en total) representan la especial atención que esta sociedad pre cerámica le prestó a la música.

12.- Idem

13.- http://sisbib.unmsm.edu.pe/bibvirtualdata/publicaciones/antropologia/2000_n11/a01.pdf 
Luego de un experimento musical con réplicas de estas flautas, hemos obtenido muchas posibilidades musicales lo que nos indica que fueron grandes conocedores de la música ${ }^{14}$. Al parecer también conocieron un tipo de idiófonos raros hoy en día, se encontraron un grupo de caracoles agrupados que muy bien pudieron haber estado atados por cuerdas para lograr la sonoridad deseada, además de dos posibles carrascas, idiófonos que pudieron haber emitido sonido por fricción: "Se han recuperado tres conjuntos musicales, conformados por instrumentos de viento, que ratifican la práctica musical colectiva y la organización compleja en la sociedad de Caral. Ellos estuvieron asociados con caracoles, como instrumentos de percusión. Las actividades religiosas y sociales incluyeron ejecuciones musicales, a cargo de grupos especializados en esta elaborada expresión artística. El arte musical tuvo un rol importante en las actividades de la población; esta tradición ha continuado como parte de la herencia cultural de las sociedades andinas de todos los tiempos". ${ }^{15}$

\section{LAS "ANTARAs" de CARAL: las PRiMeras flautas de PAN}

No cabe duda que la música debió haber jugado un papel muy importante en esta sociedad a juzgar por la gran cantidad de instrumentos musicales (aerófonos) que se han encontrado. Después de este juego de 32 "flautas traveseras", adquieren una gran relevancia el hallazgo de tres flautas de pan hechas de carricillo o cañas (de 5,3 y de 2 tubos respectivamente) (Figura 6).

Sobre las flautas de pan de Caral, se dice que "dentro de las ofrendas enrejadas se recuperaron tres antaras de carricillo (Phragmites australis); una de ellas consta de tres tubos, otra de dos tubos y la tercera de cinco tubos. Hay además, dos fragmentos de antara, de materia prima desconocida" (Shady 2008). Estas, nos asegura el antropólogo del Proyecto Caral, Carlos Leyva ${ }^{16}$, pertenecen a un solo contexto e imposible que se trate de "antaras" de posteriores períodos al primer asentamiento en Caral.

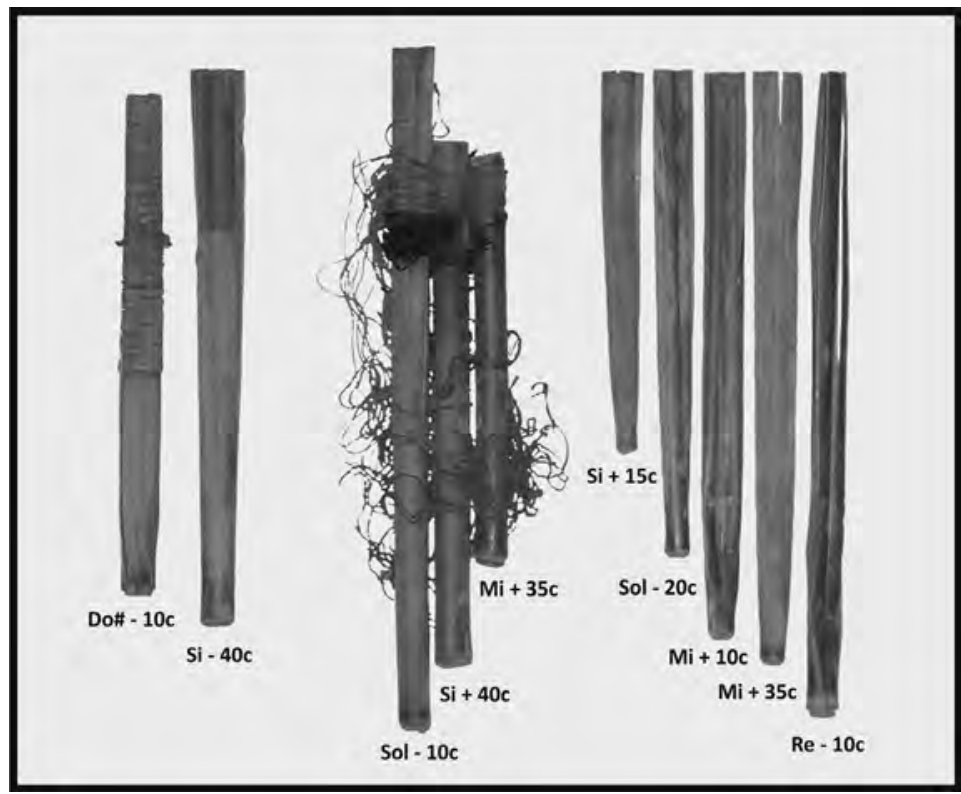

Figura 6: Flautas de Pan halladas en Caral, construido de "carricillos" en tiempos del Pre cerámico Tardío (3000 - 1800 a.C.), posiblemente las primeras flautas de Pan arqueológicas.

14.- Paul Huarancca Parco, músico "vientista" de la ENFJMA ha realizado algunas grabaciones profesionales con esta flauta, asimismo en nuestro proyecto de enseñanza a la población de Caral hemos utilizado este instrumento al igual que las "antaras" para realizar talleres de aprendizaje con niños, para lo cual hemos compuesto varias melodías con estos instrumentos musicales.

15.- En: http://www.caralperu.gob.pe/caralperu/civilizacion/civilizacionmusica.html

16.- Carlos Leyva es integrante del proyecto Caral y en una entrevista personal nos ratificó la antigüedad de las “antaras" Caral. El año 2012, realizamos talleres de "antaras" (con réplicas) en el actual poblado de Caral, dirigido principalmente a niños. 
Sobre ellas se dice que pertenecerían a una élite, puesto que fueron halladas formando una especie de ritual de entierro. En este sentido encontramos posiblemente una relación de la música con las élites de poder quienes además ostentaban el conocimiento de la magia, de la religiosidad y de la medicina. Organológicamente podemos decir que fue construida de manera sencilla en cañas ("carricillos"), material orgánico que felizmente se conservó gracias a la geografía de la zona. Se puede observar cómo su carácter morfológico continúa en las flautas de pan actuales, 5000 años después.

De acuerdo al contexto en el que fueron descubiertos, los arqueólogos del Proyecto Caral han determinado que se trataría de tres flautas de pan: una de 5 tubos (agrupadas sin ataduras), otra de 3 tubos (con evidentes amarres) y la última de 2 tubos también sueltas. Las notas musicales aproximadas de cada "antara" las hemos considerado en la imagen del original (Figura 6) cedidas amablemente por el Proyecto Caral. Las dimensiones aproximadas de estas flautas de pan son: El de 5 tubos (de menor a mayor: 174, $229,259,271$ y $297 \mathrm{~mm}$ respectivamente). El de 3 tubos $(128,171,219$ $\mathrm{mm}$ ) y el de 2 tubos (164 y $182 \mathrm{~mm}$ ) (Figura 7).

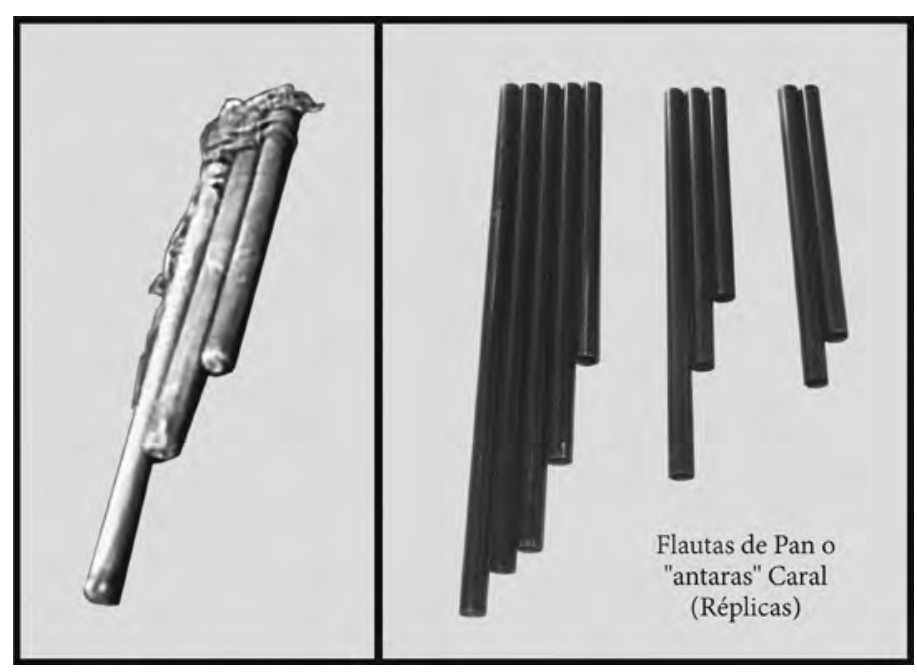

Figura 7: Réplicas de las flautas de Pan o "antaras" halladas en las excavaciones del Centro Arqueológico o "ciudadela" Caral (Supe, Lima). Su antigüedad comprobada es de 2,750 a.C. Es sorprendente la similitud organológica con las "antaras" actuales, casi 5000 años después.

Finalmente, sean las "antaras" Caral las primeras, o por supuesto otras que se habrán perdido con el tiempo, sí podemos afirmar que las flautas de pan habrían sido los primeros artefactos sonoros o más específicamente los primeros instrumentos musicales de tipo melódico utilizado por el hombre andino en su desarrollo junto a los silbatos:

"The principle of the pan-pipe is probably very old. It is really nothing but a closed pipe blown according to the "key" principle. We have found such pipes among a number of South Americans tribes, and they are as casy to invent as the simple fruit-shelc whistle" (Izikowitz 1934: 41).

\section{LA FLAUTA “TRAVERsa” Kotosh}

Considerado como uno de los templos más antiguos del Perú y de América, Kotosh está situado en el actual departamento de Huánuco y tiene una antigüedad aproximada de 4000 años. El templo más simbólico y que pertenece a la época Mito (2000 a 1500 a.C.), es el de "Las Manos Cruzadas". De acuerdo a los estudiosos del tema, en este tiempo y sociedad ya se comprendía el "dualismo complementario andino" que estaría representado en el par de manos bajo el nicho a la izquierda de la hornacina central y su contraparte, otro par de manos bajo su respectivo nicho. De este sitio tenemos un artefacto sonoro, que si bien César Bolaños (2008) lo consideró un silbato ${ }^{17}$, creemos que en realidad se trata de un instrumento musical, específicamente de una flauta tipo travesera o traversa. Esta con-

17.- http://revistas.ucm.es/index.php/REAA/article/view/REAA0909110219A/22847 
fusión de "silbato" por flautas tipo traveseras ya lo hemos visto también en el caso de los hallazgos de Engel en Chilca (Figura 9). Llegamos a esta conclusión por su total semejanza al modelo de las flautas Caral, los cuales han quedado demostrados que se tratan de instrumentos musicales. Esta fue construida en hueso, se trata de un instrumento bastante pequeño $(6,2 \mathrm{~cm}$. con un diámetro promedio de $0,7 \mathrm{~cm}$.) y posee un

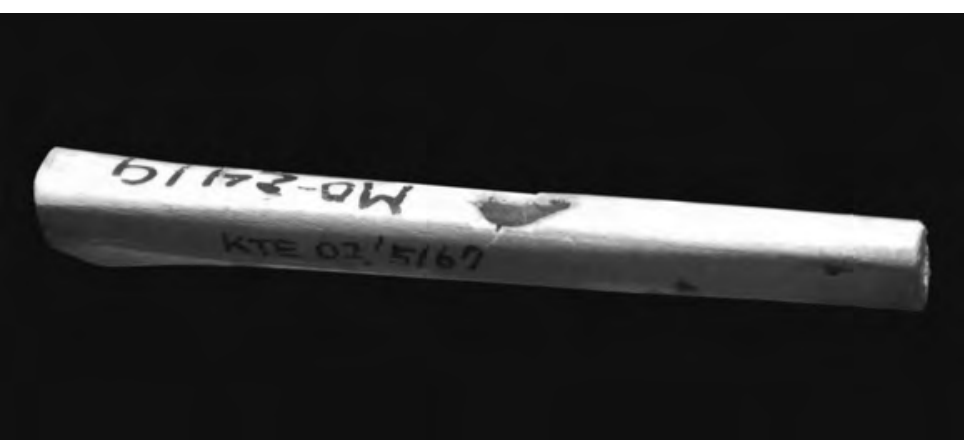

Figura 8) Flauta encontrada en el Templo de las manos Cruzadas en Kotosh a finales del Arcaico y cerca ya del periodo Formativo u Horizonte Temprano. MO-2419 - MNAAHP solo agujero de embocadura en el centro de la misma (Figura 8).

Entonces los instrumentos arqueológicos del periodo Arcaico se resumen en tres tipos de aerófonos muy bien distinguibles: 1) la flauta de ducto directo o vertical tipo "quena" proveniente de la aldea de Chilca, fue construida en madera con una dimensión promedio de $30 \mathrm{~cm}$. y tendría una antigüedad aproximada de 5765 años. 2) Flautas de ducto horizontal o tipo "traveseras" construidas en hueso de pelícano halladas en el sector de Caral (antes Chupacigarro) y que tendrían una antigüedad promedio de 4515 años. 3) Las flautas de Pan tipo "antaras" construidas en carricillos y halladas en la misma escena de Caral, cuyas características ya fueron descritas y tienen una antigüedad aproximada de 4750 años.

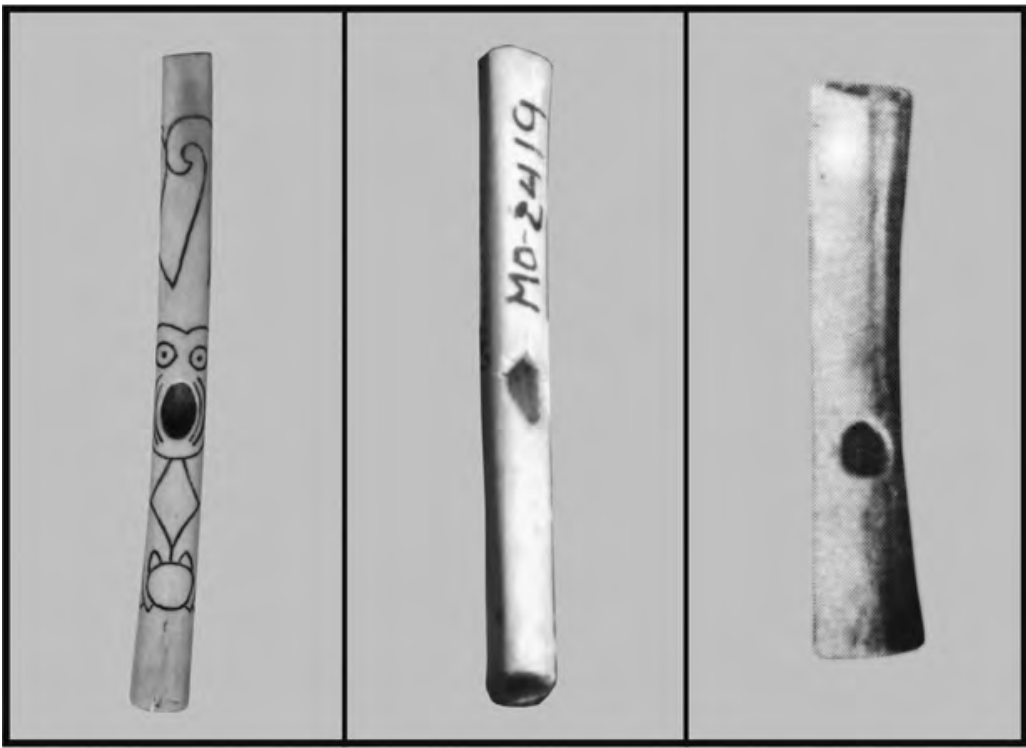

Figura 9: Flautas traveseras o traversas del Arcaico y Pre cerámico en nuestro territorio. Se trata de un modelo que aparece tempranamente junto a los modelos de "ducto directo" o tipo "quenas" y que perdurará hasta nuestros días: (9a) flauta Caral, (9b) flauta Kotosh, (9c) flauta Chilca. 


\section{II}

\section{PERÍODO FORMATIVO / INICIAL / HORIZONTE TEMPRANO}

\section{(APRox. 1800 - 200 A.C.)}

\section{LA APARICIÓN DE LA CERÁMICA}

Además de la aparición de la cerámica y la orfebrería en nuestro territorio se evidencia un gran desarrollo de la arquitectura y sobre todo de los centros ceremoniales religiosos en esta época del Formativo. Entre los principales asentamientos sociales de este periodo tenemos a Cupisnique, Kunturwasi, Sechín, Nepeña, Kaluyo, Haldas, Moxeke, Patazca y otros. Pero el asentamiento de Sechín en el valle de Casma (Ancash) será uno de los más importantes. En este tiempo se inicia el indiscriminado uso de la cerámica también para la construcción de algunos artefactos sonoros y de los instrumentos musicales de vientos, entre ellos las flautas de Pan, que hasta entonces habían sido confeccionadas en base a materiales orgánicos pre existentes como las cañas (carrizos), las plumas y los huesos (de aves y otros animales menores).

\section{Sechín (1800 A.C.) Formativo Inicial}

La sociedad Sechín viene desde el periodo anterior, del Arcaico y Pre cerámico, pero hacia el 1800 a.C., posiblemente antes de que Chavín se expandiera, este ya se desarrollaba como una sociedad más compleja donde la arquitectura y la cerámica jugaron un rol preponderante. El centro arqueológico Sechín se encuentra ubicado en el departamento de Ancash, provincia de Casma a unos 10 kilómetros de distancia del mar. No se conoce exactamente el alcance territorial que tuvo pero se han confirmado algunos sitios arqueológicos pertenecientes a ésta, como el Cerro Sechín, Sechín Alto, el complejo arqueológico de Pampa de las Llamas Moxeke, la Galgada, los templos de Punkurí, Cerro Blanco, la fortaleza de Quisque, la muralla de Nepeña entre otros. Los centros ceremoniales y por tanto los rituales ya venían desde hacía cientos de años atrás, por lo que los artefactos sonoros (y en alguna medida los instrumentos musicales) ya formaban parte de estas sociedades participando principalmente en momentos de ritualidad muy profusos y constantes por entonces.

El hallazgo de una huaylla quepa o pututo (strombuss galeatus), el más antiguo de América, en el centro ceremonial de Punkurí por Julio C. Tello en 1933, evidencia que antes del esplendor Chavín, ya se hacía uso de este artefacto sonoro para casos de ritualidad y religiosidad; este tiene grabado los detalles de una mano izquierda que representaría la sujeción del instrumento. Sin embargo, no se puede considerar un instrumento musical en sí mismo, básicamente por su carácter monofónico (Falcón, Martínez y Trejo 2005). Luego la cerámica fue utilizada para la construcción de otros artefactos sonoros como los membranófonos ("bombos"), uno de ellos fue hallado en la zona principal de Sechín (Casma), de modelo cilíndrico de doble membrana construido en cerámica (Bolaños 2007: 72). También tenemos una flauta de pan una "antara"

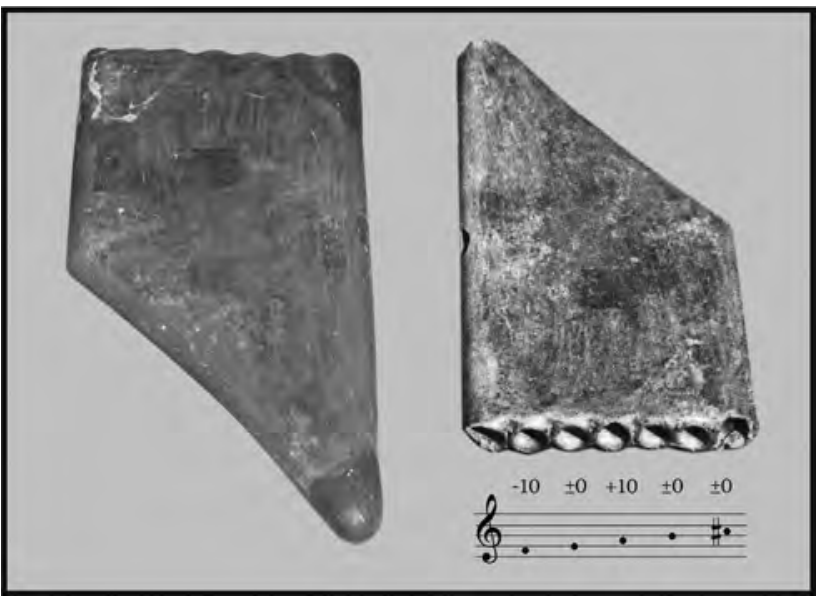

Figura 10: Flauta de pan proveniente de Casma del sitio de Sechín (Museo de Sechín) de inicios del periodo formativo construido en cerámica. (10a) Imagen tomada por el autor en el Museo de Sitio de Sechín (10b) Imagen y notas musicales tomada de Bolaños (2007: 72).

(Figura 10) y los restos de muchas otras (Figura 11). 
De este y de los posteriores tiempos, se encontraran abundantes restos de lo que habrían sido las primeras flautas de pan construidas en cerámica. Sin embargo, sólo se han encontrado fragmentos, lo que no permite un mayor análisis musical. Tampoco sabemos si estas fueron destruidas a propósito (como ritual de despedida) o en su defecto esto sucedió por acción del tiempo:

- En la Galgada "Los artefactos más distintivos incluyen puntas o cuchillos de pizarra pulida y antaras" (Proulx 1985; Pozorski y Pozorski 1987: 103; Wilson 1988).

- En el templo de Los Pilares (Chankillo, Casma): “... se halló ofrendas de antaras de cerámica y mullu, mientras que en basurales a su alrededor se halló numerosos restos de vasijas de servir, antaras de cerámica, y restos de maíz" (Ghezzi 2007:199).

- En Caylán, que representa el centro de una nueva tradición que surgió en el valle de Nepeña, igualmente nos dicen que "...se han recolectado restos de fragmentos de antaras en el Montículo Principal, en las plazas hundidas, así como en los diversos pozos de prueba" (Chicoine e Ikchara 2008).

- Mercedes Cárdenas (1998:61) nos dice que en los valles de Chao y Santa se registran restos de flautas de Pan pertenecientes a este período.

- Hugo Ikehara (2008: 381), en el valle de Nepeña señala que "En las excavaciones en Kushipampa se recuperaron artefactos, restos líticos, restos de vasijas y antaras de cerámica".

- Para el caso del valle de Casma, Henning Bischof sostiene que "la antara de cerámica encontrada con el conjunto Rosario del cerro de Sechín, junto con algunos fragmentos de otras..." pertenecería al período Patazca, posterior al período Aldas del cerro de Sechín (1400 - 1000 a.C.) (Bischof 2009).

- También Shibata vuelve a mencionar la presencia e importancia de estos aerófonos andinos en Cerro Blanco de Nepeña perteneciente al Formativo: "Las antaras y los discos perforados de tiestos reutilizados son muy comunes, en tanto que la obsidiana deja de ser frecuente".

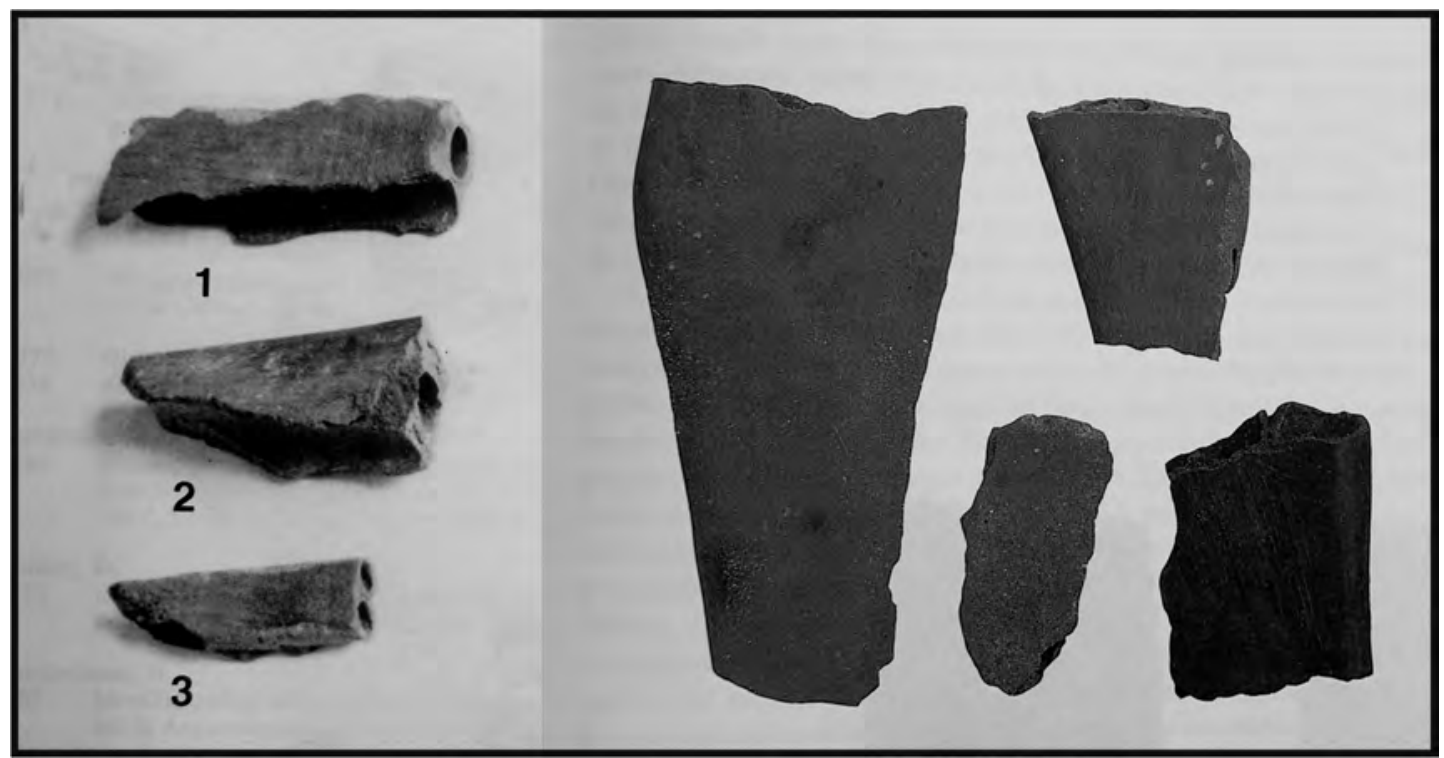


Hacia mediados del formativo, en pleno apogeo de Chavín, Federico Engel registró una flauta de Pan procedente del valle de Casma y Nepeña (Ancash) de la cultura Sechín y/o Nepeña que fuera luego dominado o influenciado por la cultura Chavín ("... una antara claramente del tiempo de Chavín", nos dice). Esta fue confeccionada con carricillos, habría tenido unos nueve o diez tubos y se encuentra (bastante deteriorada) en el museo del MUNABA (Figura12).

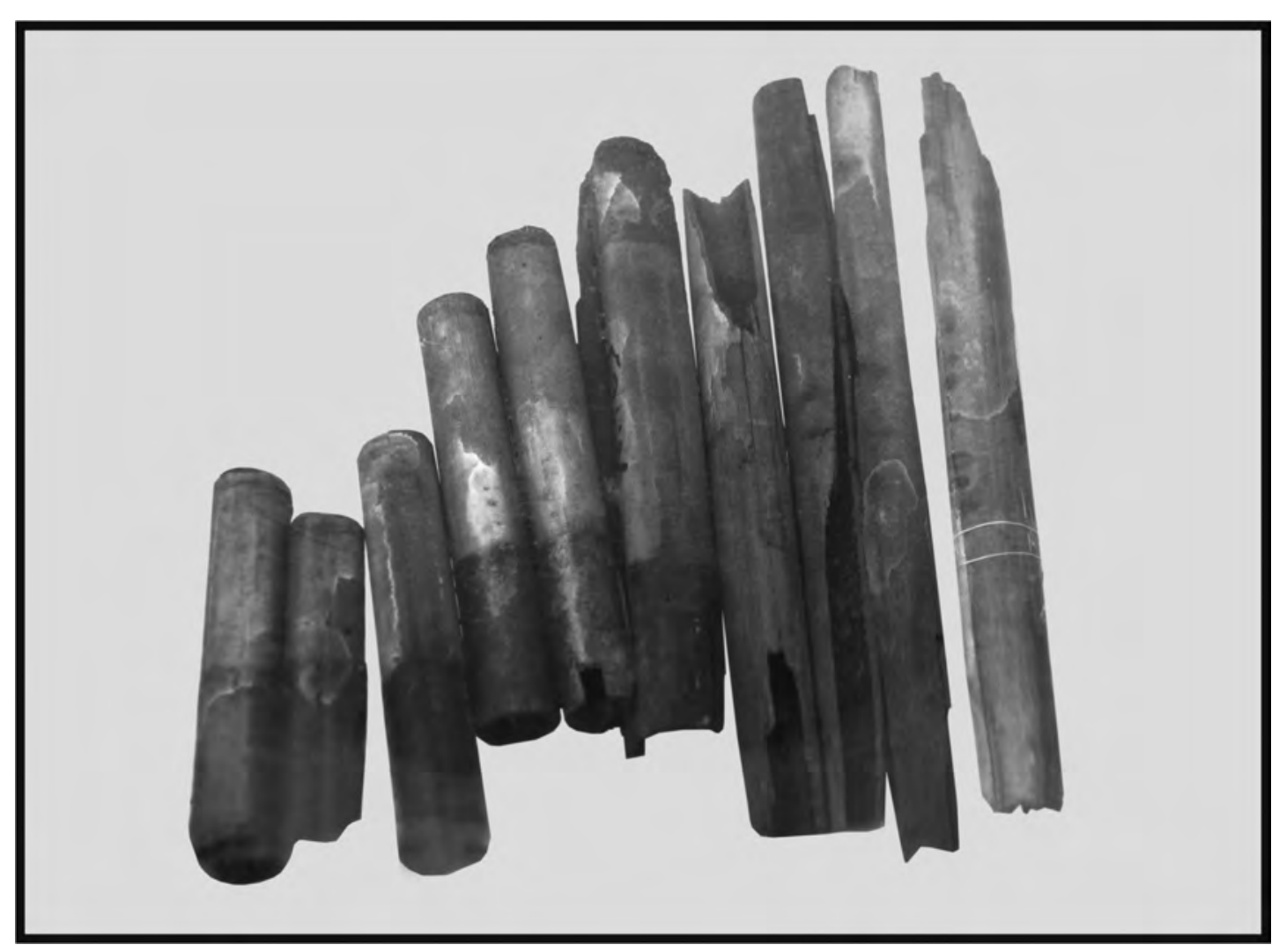

Figura 12: Flauta de Pan del periodo Sechín hallada en Nepeña por el Federico Engel (MUNABA). Construida en "cañas" (carricillos), una tradición que viene desde el Arcaico.

Luego en la sierra de Ancash, de Capilla Tardío de Huaricoto (del Formativo Tardío) tenemos: "Antaras o silbatos también fueron recuperados los cuales consisten de tubos cerámicos encajados en dos losas delgadas de arcilla. Los tubos fueron hechos de un molde, el interior es pulido y no marcado y las paredes pueden ser muy delgadas (1 a $2 \mathrm{~mm}$.). Su exterior luego fue pulido a un bajo lustre y la pieza era cocida en una atmósfera oxidante seguida por un tiznado superficial." (Burger 2004: 41). Sobre el mismo se concluye: "Estos instrumentos (antaras o silbatos) fueron producidos por moldajes de franjas, una especial técnica cerámica no usada en otras vasijas (Menzel, et al. 1964) y separando de la evidencia arqueológica y etnohistórica, fueron usados en contextos públicos, principalmente en festividades religiosas. Similares instrumentos han sido recuperados en sitios del Horizonte Temprano como Nepeña (Proulx, 1973) y Casma (T. Pozorski y S. Pozorski en comunicación personal), pero no en Chavín de Huántar" (Burger 2004: 42). 


\section{Cupisnique (1500 - 500 a.C.) Formativo Medio}

En el norte peruano, entre los departamentos de La Libertad (Virú), Lambayeque (Motupe) y Cajamarca (Kuntur Wasi y Tembladera), encontramos la presencia de esta primigenia cultura, su duración se extiende hasta los tiempos del esplendor Chavín dejándose influenciar por esta. En estos, si bien no encontramos muestras de flautas de Pan, al parecer quedan algunas evidencias de las flautas de un solo tubo ("quenas") en algunas cerámicas que analizaremos más adelante. Entonces es seguro que no debió ser extraño para estas sociedades conocer las flautas tipo "antara", las que de seguro fueron construidas en cañas (tradición que habría de continuar indefectiblemente con Moche) por lo que ha sido difícil su ubicación.

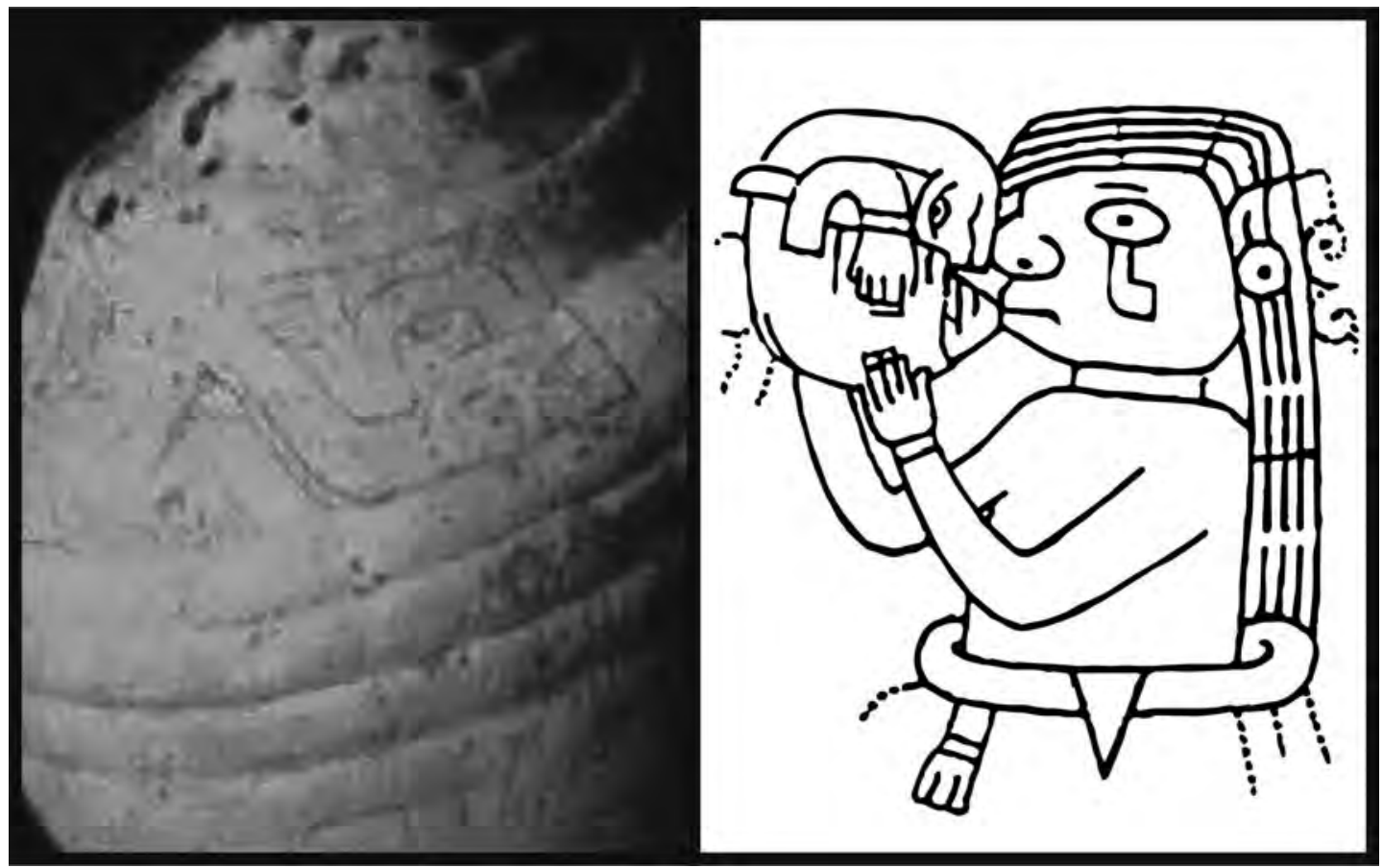

Figura 13: Detalles del strombus galeatus hallados en las tumbas Cupisnique de Kuntur Wasi (Cajamarca), representa claramente al tocador de este aerófono.

QALUYo (1000 - 400 A.C.)

En la sierra sur altiplánica, con posibles conexiones con la alta cultura Chavín, se desarrollan en este período la cultura Kaluyo (o Qaluyo) y posteriormente Pukara junto a otras de las que no tenemos desgraciadamente vestigios del uso de flautas de Pan. Sin embargo, tengamos en cuenta que algunos investigadores han sustentado que en el sector altiplánico no se tienen muestras arqueológicas debido a que probablemente estas fueron construidas en cañas y no se habrían podido conservar por la geografía y el clima. Pero, tampoco se han encontrado otros tipos de pruebas de esta existencia, como podrían ser las iconografías, pinturas, tejidos, cerámicos y otras representaciones. 


\section{Chavín (1000 - 500 A.C.) / Formativo Medio y TARDío}

No encontramos pruebas tangibles de flautas de Pan en el centro primordial de esta cultura (Callejón de Conchucos, Ancash), donde sí se ha encontrado gran cantidad de los famosos aerófonos llamados huaylla quepas (pututos) los cuales eran construidos de caracoles especiales (strombus galeatus) traídos de la costa ecuatoriana. Por la profundidad de sonido que pueden emitir y su evidente monofonía (monodia), es seguro que estos fueron usados en rituales mágico-religiosos para generar efectos sonoros muy peculiares y no como instrumentos musicales. Sin embargo, al parecer en sociedades dependientes o influenciadas por Chavín se encuentran algunas muestras como el que presenta Jeffrey Quilter (2005: 66), un ceramio de la época Chavín tocando una posible flauta de un conducto (modelo quena), que presentamos en la figura 14a y cuya leyenda dice: "the distinct north coast style of Tembladera was part of the Chavin world. The ear ornaments of this ceramic flute player are also found on the lanzon at chavin, but his facial markings and loincloth mean he is not from the central higlands. throughout the Andes, music was used to summon divinities". Sin embargo, sobre ello tenemos nuestros reparos.

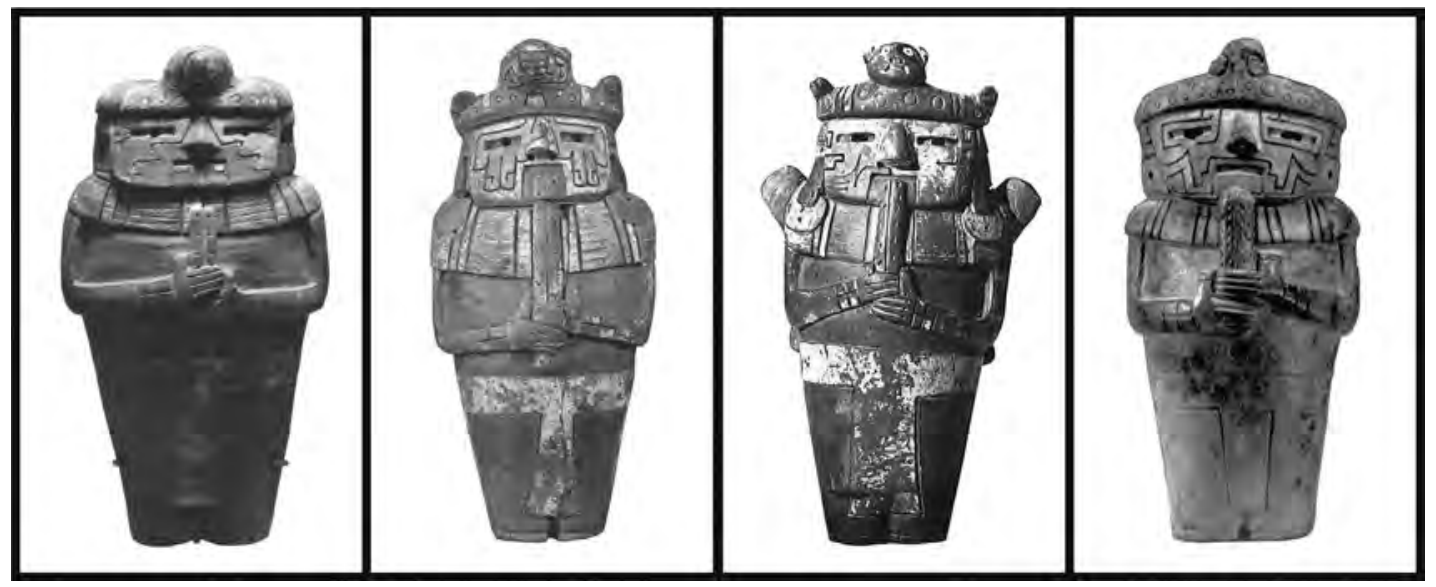

Figura 14: Posibles músicos del sitio o estilo "Tembladera" del tiempo de Cupisnique y Chavín, así son registrados en algunas bibliografías. Sin embargo, estamos convencidos que representan a un personaje especializado seguramente en el uso de la planta alucinógena/medicinal del "San Pedro".

Las otras imágenes de "músicos" de la figura 14, también provienen del sitio de Tembladera (estilo tembladera del tiempo Cuspinique y Chavín) en Jequetepeque, Cajamarca. La figura $14 \mathrm{~b}$ es presentado como: "Figure of a flute player, Jequetepeque Valley, Peru; Templadera style, early Horizon, c. 900-200 BC; Ceramic. Dallas Museum of Art, Dallas, Texas". Para la figura 14c se indica "CHAVIN - style Tembladera Cajamarca, Late C. Dignitaire jouant de la flûte. 800 to 400 B.C.E." Mientras que sobre la figura $14 \mathrm{~d}$ se dice: "Cerámicas Cupisnique en donde se representan hombres con un tocado de felino sujetando el cactus trichocereus. El de la derecha tiene en la espalda las típicas 'alas' que se aprecian en las iconografías de algunas estelas en Chavín (Sharon 2001, Lumbreras 2007)". En una revisión de una y otra posibilidad, llegamos a la conclusión de que se trata del mismo personaje (es) y este ostenta un cargo de importancia (líder religioso, político, sacerdote o curandero) de algún poblado o anexo (¿Tembladera?), muy influenciados por el centro religioso Chavín quienes hacían un cotidiano uso de la planta llamada San Pedro o Huachuma (Trichocereus sp.), tanto en actos rituales de poder, religiosidad o medicinal. El aspecto de sujeción de la posible "flauta", la inexistencia de otras evidencias de "flautistas" en las sociedades de la época, el diseño de las supuestas "flautas" (con muchos agujeros paralelos) nunca visto en otras cerámicas y por supuesto su clara semejanza con el uso y consumo del San Pedro, nos lleva a esta conclusión. 


\section{La sociedad Paracas (500 a.C. - 100 d.C.) / Formativo Tardío y Final}

Los Paracas se desarrollaron alrededor de la península del mismo nombre en el actual departamento de Ica. Fue excavado por el arqueólogo peruano Julio César Tello y Toribio Mejía Xesspe entre 1925 y 1927 quienes pusieron al descubierto restos de lo que sería una de las más importantes sociedades del tiempo Formativo. Más aún en lo que respecta a nuestro tema, pues significó el inicio de una gran etapa para las flautas de Pan pre colombinas, proceso que se encumbrará con la sociedad Nazca.

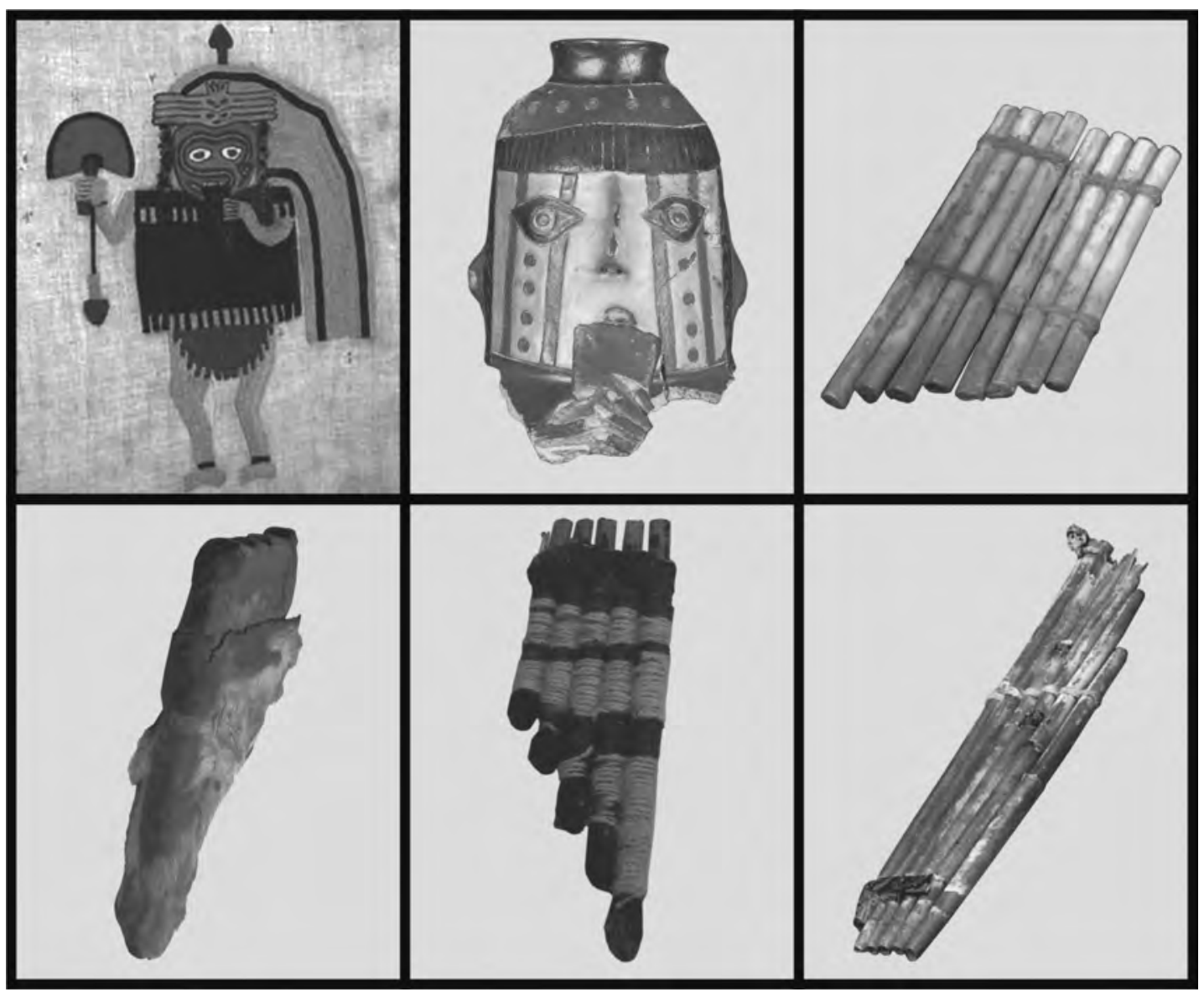

Figura 15: La diversidad de las flautas de pan Paracas, lo evidencian como el primer gran punto de desarrollo de estos instrumentos musicales: (15a) Un "antarista" bordado en el gran Manto Blanco de Paracas (MAASM), (15 b) Cerámica con músico "antarista" (MAPCH), (15c) "Antara" de huesos (MNAAHP), (15d) "Antara" de cerámica forrado por un cuero de animal (MNCP), (15e) "Antara" de cañas o carrizo con envoltura de hilos de algodón (MMCP), (15f) "Antara" de Cañas (MNAAHP). 


\section{Los Paracas y el gran inicio de las flautas de Pan}

En la sociedad Paracas observamos claramente el inicio de una gran época para las flautas de pan: hicieron uso de diversos materiales para su confección como las "cañas" o carrizos, los huesos de ave, las plumas y por supuesto incorporaron profusa y creativamente la cerámica logrando ejemplares únicos e irrepetibles. La sociedad Paracas es la que más cantidad de restos físicos nos ha heredado (después de Nazca) y con una diversidad morfológica no vista hasta entonces (Figura 15). Pero fundamentalmente tenemos dos logros organológicos y acústicos impresionantes y trascendentales que han llegado hasta nuestros días: 1) El conocimiento (posible invento y uso) de las "antaras" de "tubos complejos" (también llamados "antaras" pteroformes, bulbosiformes o fusiformes) y 2) La aparición de la "hilera secundaria", conocido y utilizado hasta nuestros días en los sikus (un tipo de flauta de pan) como "resonador".

Así, de acuerdo con las evidencias arqueológicas en la cultura Paracas (período Cavernas), estas eran confeccionadas en plumas y huesos (de aves) principalmente: "Momia V-23. Es un fardo grande cubierto con varios tejidos burdos de algodón, contiene los restos de un individuo adulto, varón (...) Los tejidos del envoltorio se hallan sumamente quemados por el tiempo. Sin embargo, se logró salvar algunos fragmentos como (...) una quena de hueso, de aspecto humano; una antara oflauta de Pan formada con varios tubos de hueso de aves marinas..." (Tello y Mejía 1979: 172). En la transición al período Paracas Necrópolis, se puede notar la presencia de la cerámica: "... antara o flauta de Pan (de cerámica) con cinco tubos prefabricados e incrustados en la pasta de arcilla gris” (Tello y Mejía 1979: 308).

\section{1) La “antara compleja” de Paracas}

En esta etapa aparece una particular flauta de Pan que desgraciadamente desaparecerá con el surgimiento del modelo "Nazca clásico" prácticamente en los mismos territorios donde floreció la sociedad Paracas. Estas "antaras" se caracterizan por poseer tubos de dos o más diámetros diferentes en su misma extensión (tubos "discontinuos"), formando muchas veces una especie de "bulbo" al iniciar el tubo (casi en su centro) para terminar finalmente en punta (figs. 16, 17 y 18). César Bolaños llama a estas flautas de pan Paracas, modelo pteforme, pteromorfo, de tubos fusiformes o bulbosiformes (estrecho en los extremos y ancho en el medio, tipo "ala de ave"): "El modelo Paracas, de cerámica, se identifica por su perfil pteforme, de morfología tubular cilindro-fusiforme y por sus embocaduras, que son ásperas al deslizar los labios" (Bolaños 1988: 12).

Hemos observado y experimentado que esta peculiaridad le permite a un mismo tubo emitir dos o más sonidos o "notas musicales" juntas o a la vez (sonidos de batimento), haciendo o sonando como una especie de armónicos o multifonías (ciertamente incómodos para nuestros "acostumbrados" oídos), dependiendo de la postura del tubo y de la técnica del soplo (posición de labio y ataque).

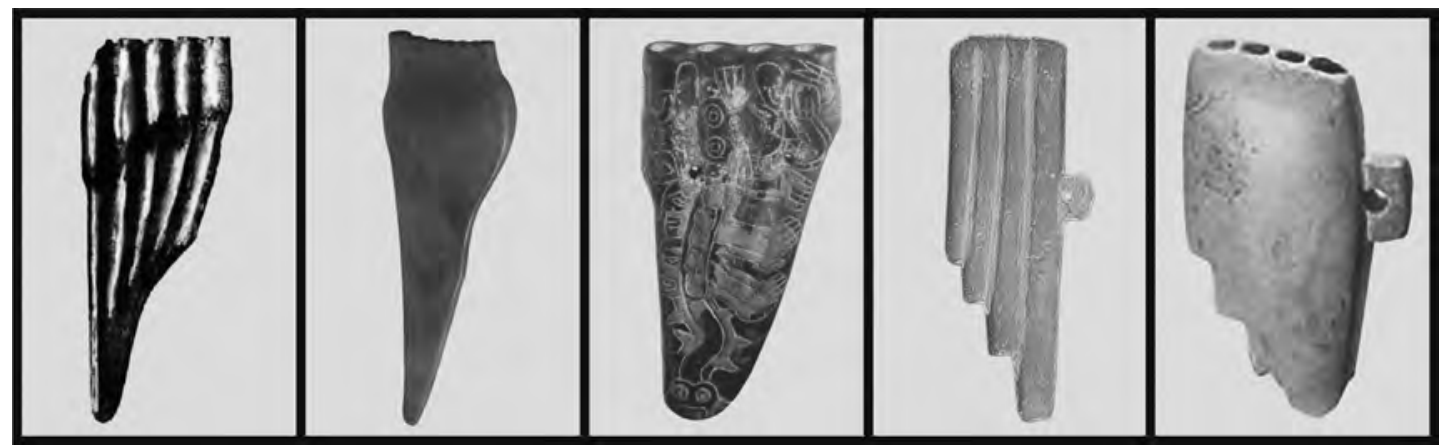

Figura 16: Flautas de Pan cuyos orificios internos son asimétricos (de "tubos complejos") sería de originado en el periodo Formativo con Paracas y se extendería por otras zonas, principalmente hacia el sur: (16a) Paracas, (16b) Salinar, (16c) Nazca, (16d) Yura (Bolivia) y (16e) Aconcagua (Chile). 


$$
\text { PII }
$$


Este tipo de sonoridad ("profundamente andina"), los encontramos o sobrevive en la actualidad por ejemplo: en los conjuntos de tarkas en el altiplano, en los conjuntos de pifilcas y de flautas de chino en Chile, en las flautas "roncadoras" en la sierra norte peruana, en los conjuntos de wapululus, lawa k'umus, chaqalladas y otros del altiplano peruano, en los conjuntos de pinkuyllus de Cusco y de pinkillus de Potosí (Bolivia) y finalmente en los mismos conjuntos de sikuris altiplánicos, en su forma de tocar como "rajando" los tubos y el efecto sonoro que aportan estos "resonadores" o filas secundarias (nunca tocadas) adheridas a las filas principales de las flautas de pan denominado sikus.

Este modelo eminentemente Paracas, se replica en la flauta de Pan Salinar de la costa norte peruana perteneciente también al periodo Formativo, luego continúa en un primer tiempo con la cultura Nazca antes de decaer en el caso peruano. Arnaud Gerard estudia una flauta de Pan (al que denomina "ayarachi") de Yura (Bolivia) que tiene el mismo patrón de "tubos complejos" y el mismo modelo es revisado por Pérez de Arce en varias "antaras" de Chile (culturas Diaguita, Atacama, Aconcagua y Mapuche). Es por tanto un modelo bastante difundido hacia la región sur andina (figs. 16 y 17).

Pérez de Arce (Chile) y Arnaud Gerard (Bolivia) coinciden en señalar que la búsqueda de un tipo exclusivo de sonoridad andina empujó a la construcción de estos modelos pteroformes o bulbosiformes en las flautas de Pan como en otros aerófonos de ducto. Esta búsqueda sonora continuaría luego con la invención de los "resonadores", expresión también del sonido "rajado" (Pérez de Arce) o del sonido "tara" (Arnaud Gerard). En esta misma dirección podemos entender la existencia de los silbatos y algunas flautas "bifónicas" que emiten obviamente dos sonidos paralelos a la vez (tienen una sola embocadura) y que existen prácticamente en todas las culturas del Formativo en adelante y que a pesar de la imposición sonora occidental seguimos escuchándolos en los conjuntos autóctonos como los ya mencionados. Pero además de la fabricación y uso de esta llamativo y único modelo de flautas de pan en el mundo, tenemos otro aporte trascendental para la música andina: los "resonadores" o "hileras secundarias" (Figura 20).

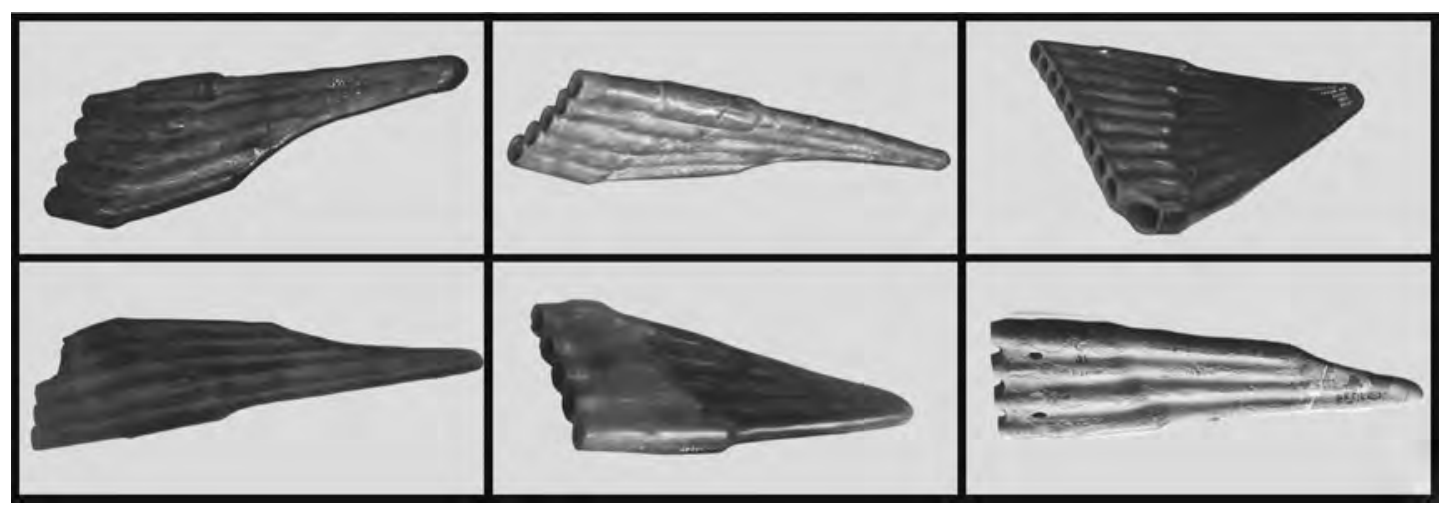

Figura 18: Flautas de Pan de Paracas de modelos pteroformes, bulbosiformes, fusiformes o de "tubos complejos", se pueden encontrar rastros de estos todavía en la sociedad Nazca y se extiende por el sur hasta zonas que hoy pertenecen a Bolivia, Argentina y Chile.

18.- La denominación de "tubos complejos" y "sonido rajado" se propone estudiando a las pifilcas prehispánicas en el caso de Chile con Pérez de Arce y en el caso boliviano se propone el "sonido tara" a partir del estudio de los conjuntos de pinkillus de carnaval por Stobart, retomado por Gerard. De las características de estos aerófonos es traspolado al siku buscando un mejor entendimiento del carácter y razón de ser de los "resonadores". 


\section{2) LAS HILERAS O FILAS SECUNDARIAS ("RESONADORES") 19}

Una variedad de flautas de Pan, desde algún momento de la época prehispánica, adquiere una fila o hilera de tubos más, adjunto a la hilera principal, por eso se le dice "secundaria", es decir se forma una "antara" con dos filas de tubos. Este tipo de flauta de pan dará lugar a los sikus caracterizado justamente por el uso de la hilera secundaria a la cual denominan popularmente "tubos resonadores o hilera resonadora" debido a su posible funcionalidad inmediata ("resonar"); es decir, darle un peculiar tipo de sonoridad (como un sello de identidad). Esto justamente diferencia a las flautas de pan de modelo siku (que llevan estos "resonadores") frente a las antaras (que no llevan estos "resonadores" o "hileras secundarias"), los primeros se sitúan al sur de lo que fuera el Tawantinsuyo (sobre todo en el altiplano) y los segundos hacia el norte del mismo.

Los sikus tienen una gran multiplicidad o tipos de "hileras secundarias" que reciben también diferentes denominaciones dependiendo de las localidades y de sus posibles razones de ser o funciones: Así, son llamados carga en algunas zonas urbanas de Perú, chala en el norte de Argentina, haylli en Taquile (Puno, Perú), falsos, ch'usa, sirinu, sanq'a, marimacho, shallka, orko (Gerard 1999), phallqa, serena, siruni (Gutiérrez 2009) en algunos lugares de Bolivia y falsa (pues no se toca) también en ciertos lugares del altiplano peruano en épocas pasadas:

En las flautas de Pan de dos filas, que en Perú tienen ambas el mismo número de tubos, se distingue aquella fila que se sopla o verdadera, y la que no se sopla o falsa. Esta última fila suena una octava más arriba que la fila de tubos verdaderos. Así, hay una zampoña de doble fila en escalera que tiene las dos filas de tubos cerrados, en ella la falsa posee tubos que corresponden a la mitad de los de las filas verdadera, pudiendo dar, por resonancia con estos, la octava superior si se sopla con suficiente intensidad mientras que hay otra zampoña que tiene ambas filas de cañas del mismo largo, en tal caso, la fila falsa posee tubos abiertos para poder dar la octava superior al resonar con los tubos verdaderos (García 1982: 185).

Se trata una fila de tubos del mismo número que la principal, pero que no se toca en ningún caso, pero que los pobladores hacen alusión a que su razón fundamental de ser es el de "resonar" las cañas (el instrumento). Mientras que los estudiosos han tratado, desde Carlos Vega, encontrarle su "verdadero" sentido. Así Gerard (1999: 103) nos dice que la función de la segunda hilera ciertamente es modificar la sonoridad que puede producir una flauta de pan simple: "Una parte del flujo aerodinámico destinado al tubo principal le alcanza y le hace sonar en subrégimen, de tal manera que las series de sobre tonos de ambos tubos se suman..." (Gerard 1999: 103). En nuestra experiencia etnográfica encontramos que la hilera secundaria ciertamente le cambia el timbre a las flautas de pan logrando cierta sonoridad "multifónica", “disonante", "bifónica", "pastoso", "mezclado", “desigual”, "borroso", "vibrante”, etc. Es seguro que los conjuntos de sikus actuales tienen en cuenta que los tipos y las características sonoras que les generan los "resonadores" junto a las formas de interpretar la flauta de pan, les otorgan elementos de identidad musical, diferenciándolos unos de otros, que es una búsqueda constante en el mundo andino.

19.- Esta particularidad de los sikus (variedad de las flautas de Pan andinas), ha sido objeto de muchos e inacabados estudios: Hornbostel y Sachs 1914; Mead 1903; Vega 1946; Izikowitz 1934; González-Bravo 1948; Langevin 1992, Girault 1968, Baumann 1982; d'Harcourt 1925, Pérez de Arce 1992, Gerard 1999; Valencia 1982; 1989a; 1989b, entre los principales. 
El tema y las largas discusiones sobre los "resonadores" giran en torno a su razón de ser, su funcionalidad, sus características sonoras y físicas, aunque, todos los autores coinciden en que el objetivo principal actual es alterar ("armonizar", "mejorar", "diferenciar" o "enriquecer") el sonido de este tipo de flauta de pan (siku). Pérez de Arce y Langevin señalan que la razón de los "resonadores" (desde el tiempo pre hispánico), es la búsqueda musical constante de una sonoridad exclusiva o particular. Américo Valencia por su parte presenta a los "resonadores" en términos de "enriquecimiento musical": "Los tubos de la hilera secundaria enriquecen los sonidos producidos por los tubos de la hilera principal por la adición de armónicos pares. Estos reciben parte del soplido dirigido a los tubos principales, y emiten sonidos cuyas fundamentales son una octava de los sonidos producidos por los tubos principales". (Valencia 1989: 35). Por la misma senda, Xavier Bellenguer (2007), tomando las versiones de los sikuris de Taquile (Puno, Perú), nos dice que el fin de los "resonadores" es contribuir "al enriquecimiento armónico de cada sonido producido soplando en los tubos de la primera hilera", y cita la opinión de un fabricante de sikus en Taquile: "La segunda hilera se llama haylli, le da un bonito sabor, es su acompañante" (p. 140).

Hemos encontrado diferentes tipos de "resonadores" a lo largo del desarrollo del instrumento (Figura 19): 1) De tubos del tamaño de la mitad de los principales y cerrados en su base, mayormente afinados a la octava de la fila principal (los más comunes en la actualidad, especialmente en las ciudades); 2) De tubos cerrados del mismo tamaño que las principales o afinados a la misma notación de la fila principal (se han encontrado en algunas culturas pre incas este modelo, y en la actualidad subsisten); 3) De tubos del mismo tamaño a la fila principal pero con el extremo distal abierto en forma de tajo oblicuo (su data es igualmente prehispánica y sigue vigente en muchos casos); 4) De tubos que alcanzan una longitud de los $2 / 3$ del tubo principal, cuyos extremos distales pueden ser cerrados o abiertos con tajo oblicuo (se trata de un modelo casi extinguido); y 5) De tubos invertidos, es decir de sonido mudo: "En algunas zampoñas (por ejemplo las sikuras del norte de Potosí), algunos tubos son tapados en ambos extremos" (Walter Sánchez 1996: 102). Aunque en la actualidad ha perdido vigencia ${ }^{20}$ :

Existen flautas de Pan que tienen, en la segunda fila, los tubos invertidos, es decir, con las aberturas en los extremos inferiores $y$, por tanto, mudos. Otras con los tubos abiertos en ambos extremos, teniendo una longitud igual a la de los tubos de la primera fila y sonando una octava superior. También las hay con los de ambas filas abiertos en la embocadura y cerrados en los extremos inferiores, pero midiendo los de la segunda algo más de la mitad de la longitud de los de la primera. Se ha dicho que posiblemente el recurso de los tubos abiertos fue conocido en un principio y olvidado paulatinamente, de manera que los instrumentos actuales conservan una segunda fila de tubos, no ya con la intención de reforzar con sus octavas superiores los sonidos de la primera fila, sino para consolidar el instrumento, o bien para reducir el tamaño del mismo, o incluso para fusionar dos instrumentos en uno. Hubo una célebre controversia entre cuatro grandes especialistas en organografía, d'Harcourt, von Hornbostel, Curt Sachs e Izikowitz, acerca de la segunda fila de tubos en las flautas de Pan, que planteaba la cuestión de si esa segunda fila contribuye únicamente, como el tubo central de ciertas flautas en haz o manojo, a reforzar la solidez del instrumento, o a desempeñar el papel de acompañamiento femenino de una serie masculina al modo de la escala china o, en el caso de estar constituida esta segunda fila por tubos abiertos en los dos extremos, si ello permite duplicar con su octava superior cada nota de la primera fila; preguntas éstas que encuentran respuestas contradictorias de acuerdo con los hechos (Varela de Vega 1981:2).

20.- Se sabe de sikus que tienen los tubos de la segunda hilera invertidos, los que al parecer han perdido vigencia, particularmente no conocemos conjuntos que toquen con estos instrumentos, sin embargo hemos citado uno. 


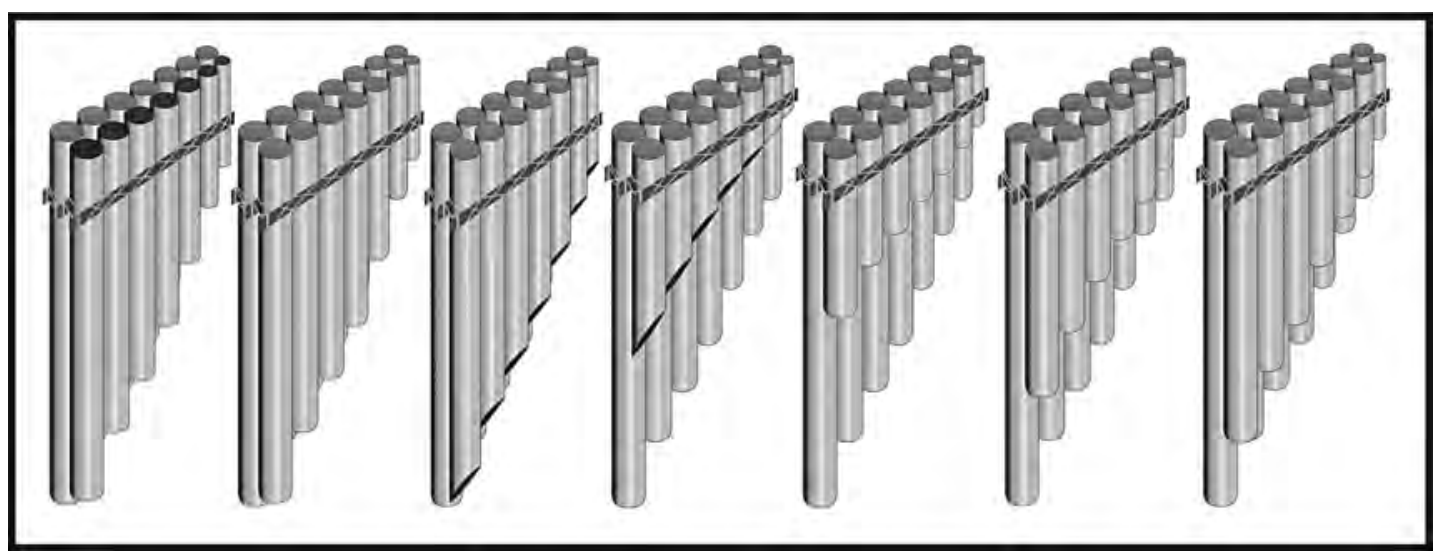

Figura 19: Modelos o tipos de "resonadores" que las flautas de Pan andinas llevan desde tiempos del Formativo y que en la actualidad caracterizan a los sikus altiplánicos

Como hemos mencionado, algunos investigadores, sugieren que el origen de las hileras secundarias o "resonadores", se encuentran en este periodo Formativo en las "antaras" de "tubos complejos" de la cultura Paracas (Pérez de Arce 1993; Haberli 1972; Bolaños 1988; Gerard 1999) 21. Sin embargo, sobre los "resonadores" propiamente hemos encontrado las siguientes versiones: Pérez de Arce menciona que el "resonador" se ve claramente en el Horizonte Medio, es decir, con la cultura Wari (600 - 1200 d.c.): "Cuando decae la antara y surge el siku" dice, sosteniendo que la diferenciación del siku respecto de la "antara" sería justamente la existencia del "resonador", así como la técnica del "diálogo musical" que casi siempre van juntas. César Bolaños (2007) por su parte nos sugiere que flautas con "resonadores" las encontramos en las culturas Chincha, Chancay, Pachacámac y Collao (es decir entre el Período Intermedio Tardío, Wari y sus postrimerías). Luego Pérez de Arce (1993: 479) hace la siguiente aseveración: "La solución acústica del tubo resonador es similar a la del tubo complejo, y se utiliza dentro de un mismo esquema musical. Siendo anterior este último, resulta lógico pensar que durante la sustitución cultural entre Nazca y Wari se debió producir el traspaso del sistema acústico desde el tubo complejo de la antara al resonador del siku". También por su parte, Isabel Aretz (1991: 51) señala que "Con los Chincha que aparecen en la costa sur aproximadamente en 1200 d.C., (y que son) ejecutantes de kenas y antaras, aparecen las antaras de dos hileras de tubos...".

Ahora podemos sugerir respaldados en la figura 20, que el conocimiento de la "hilera resonante" ya existía claramente en la cultura Paracas, es decir aparece en el periodo del Formativo Final "conviviendo" con los "tubos complejos" de la misma cultura. Esta pequeña flauta de pan Paracas construida con huesos de pelícano (pelecanus erythrorhynchos) (6425/MNAAHP), presenta dos filas de tubos casi exactos y atados en un solo amarro, lo que significa que era tañida sujetando a la vez las dos hileras y con la posibilidad de que la hilera secundaria haya estado cerrada. Es claramente una flauta de Pan con "resonador".

21.- Pérez de Arce señala que los constructores de la cultura Paracas inventaron el tubo complejo. Y luego este invento comenzó un viaje en el tiempo, el espacio y las culturas, encontrándose posteriormente en Nazca, Tiwanaku, San Pedro de Atacama, Diaguitas, Aconcagua y sur de Chile (por ejemplo la flauta del baile de chinos). 


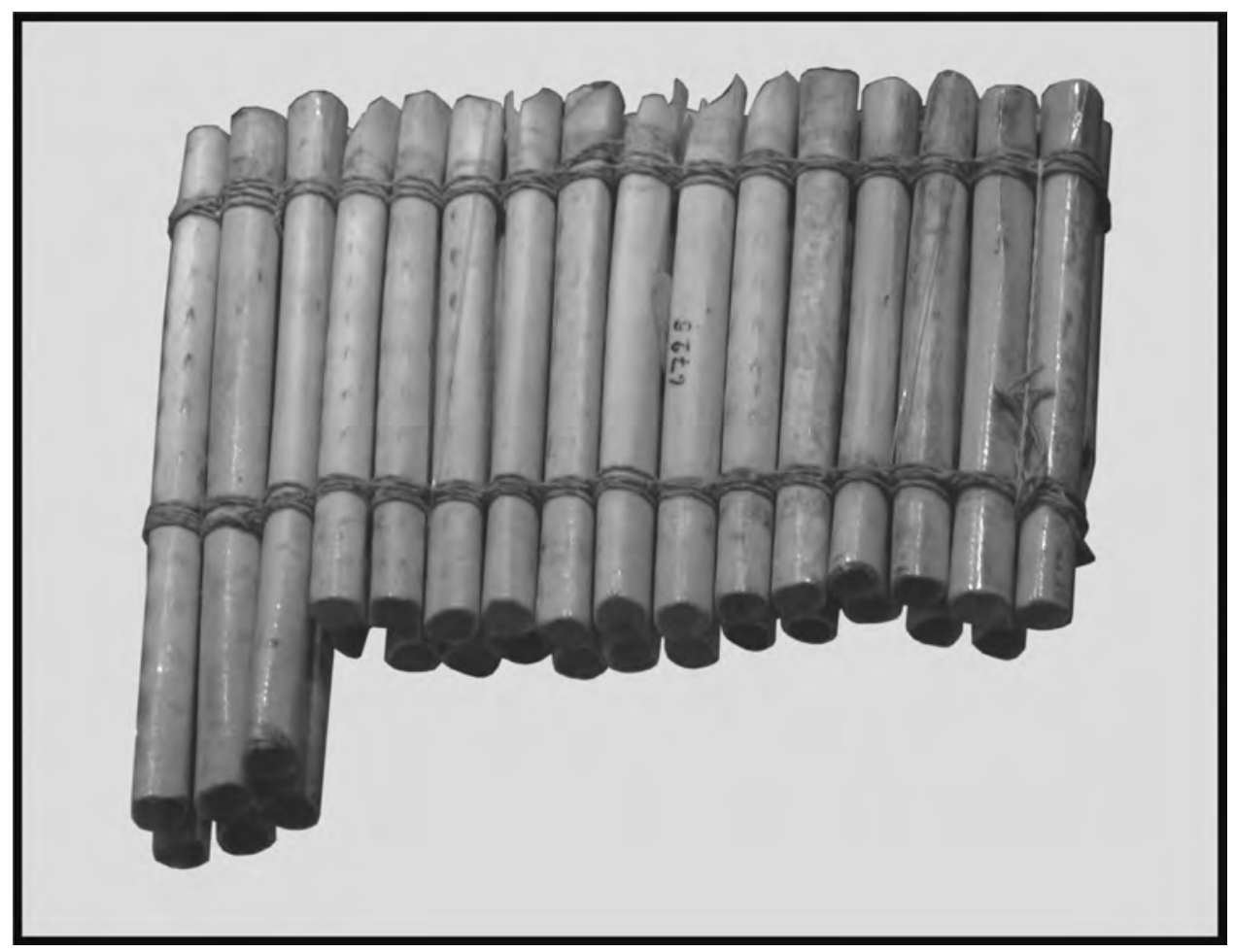

Figura 20: Flauta de pan Paracas (500 a.C.) que presenta evidentemente una fila de tubos adosados a la hilera principal de igual morfología y al que en la actualidad se le conoce comúnmente como "resonadores". 6425/MNAAHP

Sin embargo, es cierto que durante los periodos posteriores a Paracas, y antes de Wari se puede ver una disminuida presencia de las flautas de Pan con "resonadores" opacados seguro por el profuso uso y masificación de las "antaras" de cerámica de una sola hilera con embocaduras finas del periodo Nazca Clásico. Sin embargo, tenemos evidencias de continuidad de modelos con "resonador" en el periodo del Intermedio Temprano en la cultura Nazca, seguramente ligados a la tradición Paracas. Hemos hallado dos flautas de pan Nazca con "resonadores" pero construidos en cañas o carrizo que tampoco fueron extraños en este periodo "ceramista" como veremos más adelante (Figura 21).

Claro que ciertamente los modelos de flautas de pan con "resonadores" aparecerán muy clara y masivamente en el periodo de los Estados Regionales o Intermedio Tardío y con mayor nitidez en unos sectores (sur) frente a otros que prefirieron las flautas simples sin "resonadores" y que a la postre la conoceremos con el nombre de antaras propiamente, todos estos modelos muy ligados al profuso uso de las "cañas" (variedad de carrizos) en desmedro de la cerámica logrado por los Paracas y encumbrado por los Nazcas. En este periodo tardío por ejemplo tendremos una flauta de pan Chincha con "resonador" construida en cerámica, caso muy excepcional y por otro lado ya se podrá hacer una clara distinción entre los dos principales modelos de flautas de Pan del mundo andino: el modelo siku y el modelo antara. Estaremos entonces ad portas de la llegada de occidente y las crónicas nos ayudarán en algunos casos a una mejor comprensión de lo que el mundo andino precolombino había logrado en este específico tema. 


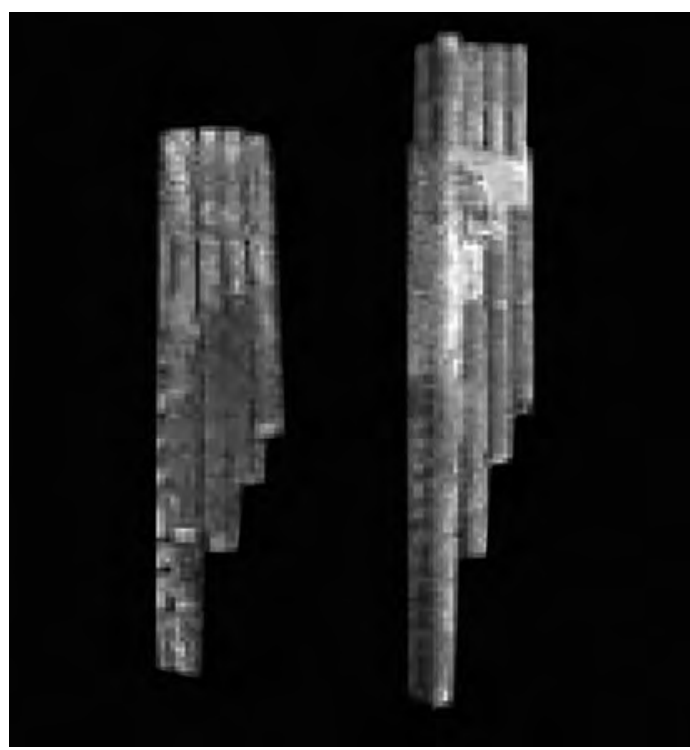

Figura 21: Flautas de Pan Nazca (200 a.C.) construida en "cañas", posee también "resonadores" de igual tamaño y material adherida a la hilera principal. La imagen ha sido extraída del catálogo oficial del Ministerio de Cultura del Perú. ${ }^{22}$

De esta manera podremos ver luego en culturas del Intermedio Tardío como Chancay (1000 - 1500 d.c.) y Chincha (1000 - 1476 d.c.) que florecieron en la costa central y sur del Perú respectivamente y que sobrevivieron todavía hasta la llegada de occidente, la presencia de abundantes flautas de Pan con "resonadores", lo que a la vez podría indicar su indefectible "dualidad complementaria". Y es que en algún momento de esta historia de las flautas de pan que venimos narrando, se adicionará a la flauta de pan una especial técnica de ejecución al que se denominará luego "diálogo musical complementario". Vale decir, flautas de pan desglosadas en dos y que son tocadas de manera alternada entre dos ejecutantes logrando sonar como un instrumento y que a nuestros días llegan bajo la denominación de sikus y sikuris y la técnica del "diálogo musical". Sin embargo, sobre esta "técnica musical" andina no hemos encontrado pruebas de su existencia en la sociedad Paracas ni en otro del periodo Formativo.

\section{Cultura Salinar (300 a.C. - 100 D.C.)}

Situada en la costa norte en los valles de Moche, Chicama y Virú. Su formación posiblemente fue luego de la culminación de la sociedad Cupisnique y Chavín en este sector, constituyendo una especie de puente con la cultura Mochica o tal vez el inicio de esta. Sin duda, las flautas de Pan que presentamos juntas (Figura 22) indican esta relación de continuidad y cambio entre Salinar y los Mochicas, donde a pesar de la distinción realizada por los arqueólogos otorgándole a uno como "antara Salinar" y al otro "antara Mochica", hay grandes semejanzas no solo a simple vista (color, textura, forma, tamaño), sino también por su estructura interna, que son a todas luces "tubos complejos" o modelos "fusiformes" de origen Paracas como ya vimos. ${ }^{23}$

Sobre estas evidentes semejanzas caben dos posibilidades: 1) Que las dos flautas de Pan pertenezcan a una de estas dos culturas. 2) Si una pertenece a Salinar y la otra a los Mochicas, entonces tenemos una clara continuidad cultural. El examen quedará para una investigación profunda sobre los mismos, revisando sobre todo el contexto de su hallazgo, el que desgraciadamente está perdido en el caso de la segunda "antara" que fue comprada a "huaqueros" quienes lo habían extraído evidentemente del área cultural Mochica pero que fue también área de culturas anteriores como Salinar.

22.- http://www.cultura.gob.pe/sites/default/files/paginternas/tablaarchivos/2013/04/

23.- César Bolaños (2007: 84) presenta además tres flautas de pan de diferente tamaño (posiblemente "complementarias" a la octava), que pertenecería a una de estas culturas: Salinar, Vicus, Mochica o Recuay, pero como forma parte de algún "coleccionista privado", esto no puede ser aseverado. 


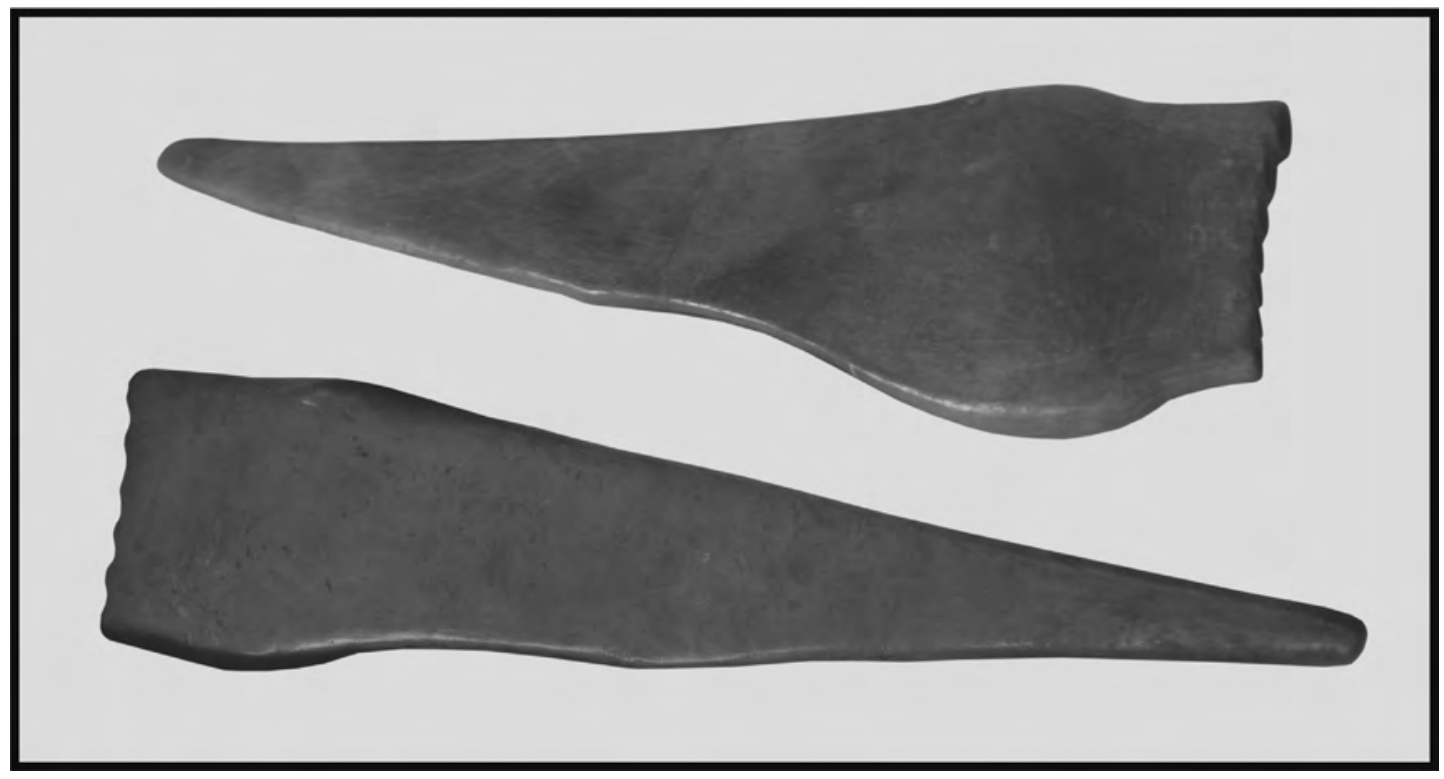

Figura 22: Flautas de pan "norteñas" de finales del periodo Formativo: (22a) Flauta de pan Salinar (MNAAHP). (22b) Flauta de pan Mochica (MC)

Por otro lado, la existencia o "recuperación" de estas flautas de pan son muy importantes en primer lugar porque se trata de una de las pocas evidencias de "antaras" físicas del tiempo del Formativo Superior en la costa norte. Pero a la vez esta carencia de instrumentos hace imposible usar la metodología comparativa que muchas veces en la arqueología resulta vital. Especialistas como Bolaños y Valencia coinciden en señalar que en estas áreas existen muy pocos los restos físicos de flautas de Pan debido a que estas fueron construidos en "cañas" (carrizos), un material orgánico altamente extinguible por acción de la geografía y el clima en estas zonas. De ser así, queda la interrogante ¿Por qué a pesar del uso furtivo de la cerámica, no lo utilizaron para la confección de este instrumento? Esto muy a pesar que en el mismo tiempo, en el sur se venía desarrollando un prolífico y calificado uso de la cerámica para la confección de las "antaras" en Paracas y luego en Nazca. Es obvio que estas dos -casi únicas-, flautas de pan norteñas de modelo "complejo", evidencian que existió una conexión entre estas sociedades. Pero aun así no encontramos una influencia determinante ni en el uso del "modelo complejo" ni en el uso de la cerámica para la confección de estos instrumento, ni en el siguiente gran periodo correspondiente al Mochica.

Una pregunta seguirá quedando sin respuesta: ¿Por qué en momentos del auge Mochica no se encuentran flautas de Pan (físicamente), a pesar de tener una gran cantidad de restos iconográficos y cerámicos de "antaristas" que incluye su uso en las más altas esferas de poder y prestigio? ¿Y a pesar de la alta técnica en el uso de la cerámica para otros usos (como los auto retratos Mochicas)? En el periodo siguiente, del Intermedio Temprano o del Periodo Clásico, observaremos el desarrollo pleno y máximo de las flautas de Pan tanto en su uso simbólico en Moche como su increíble masificación y técnica de construcción en la sociedad Nazca. 


\section{Comentarios finAles}

Hasta aquí venimos observamos cómo las flautas de pan ("antaras") y las flautas de ducto (pinkullos o quenas) son los principales "artefactos sonoros" (más allá del huaylla quepa o pututo) que acompañan el desarrollo cultural de los pobladores andinos. De entre estos aerófonos, venimos observando con mayor detalle el desarrollo de las flautas de varios tubos o flautas de pan (arbitrariamente denominadas "antaras" por la arqueología). Estas aparecen en las sociedades Pre cerámicas del Arcaico de acuerdo a los vestigios arqueológicos, aunque es lógico suponer que sus orígenes se encuentran mucho antes, pese a que no hemos hallado ninguna "antara" que cuente con los 7000 años de antigüedad (primeros tiempos del Arcaico) que señalan muchas publicaciones.

Venimos observando que el mayor desarrollo de estos instrumento se encuentra en la costa peruana adquiriendo una especial relevancia en el periodo del Formativo con la sociedad sureña Paracas, quienes inician al parecer la masificación del instrumento (de lo que posiblemente habría sido de grupos de elite ligados al poder religioso, político y médico) con el profuso uso de la cerámica. Pero no sólo ello, sino que para finales del Formativo ya contamos con dos caracteres muy esenciales para la música andina y en especial para las flautas de pan actuales: La aparición de los "tubos complejos" y del "resonador". Vale decir que estas se van haciendo cada vez más diversas y complejas adquiriendo caracteres que las sociedades andinas le irán adosando como un sello de identidad.

\section{BibLIOGRAFÍA}

ARETZ, Isabel

1991 Historia de la Etnomusicología en América Latina (Desde la época precolombina hasta nuestros días). FUNDET, CONAC, OEA. Caracas, Venezuela.

\section{BELLENGUER, Xavier}

2007 El espacio musical andino, modo ritualizado de producción musical en la isla de Taquile y la región del lago Titicaca. IFEA (Instituto Francés de Estudios Andinos). Lima.

BLACKING, John

1973 ¿Hay música en el hombre? Alianza Editorial S.A. Madrid.

BISCHOF, Hennign

2009 El periodo arcaico tardío, arcaico final y formativo temprano en el Valle de Casma: Evidencias e hipótesis. Boletín de Arqueología de la PUCP N 13, Pág. 9-54. Lima.

BOLAÑOS V., César; ROEL PINEDA, Josafat; GARCIA, Fernando; SALAZAR, Alida.

1978 Mapa de Instrumentos musicales de uso popular en el Perú. INC. Oficina de Música y Danzas. Lima.

BOLAÑOS V., César

1988 Las antaras nazca: historia y análisis. Publicación del INDEA. Lima.

2007 Origen de la música en los Andes. Instrumentos musicales, objetos sonoros y músicos de la Región Andina precolonial. Fondo Editorial del Congreso del Perú. Lima.

BURGUER, Richard

2204 Cambios Estilísticos Y Desarrollo Cultural En Huaricoto Sierra Nor-Central Del Perú. En: Arqueología De La Sierra De Ancash: Propuestas Y Perspectivas. Editor: Bebel Ibarra Asencio. Instituto Cultural Rvna. Lima Perú. 
CIVALLERO, Edgardo

2012 Flautas de Pan. En, Revista Folklore, fundación Joaquín Díaz. Edición digital Anuario 2012. En, http://www.funjdiaz.net/folklore/anuarios/rf2012.pdf

COBO, Bernabé

1653, 1956. Historia del Nuevo Mundo. Biblioteca de Autores Españoles, 1956 Vol. 81, Obras del Padre Bernabé Cobo II. Ediciones Atlas. Madrid, España. También en: http://fondosdigitales. us.es/fondos/libros/2423/11/historia-del-nuevo-mundo-por-el-padre-bernabe-cobo-dela-compania-de-jesus/

ENGEL, Fréderic André

1988 Ecología prehistórica andina: el hombre, su establecimiento y el ambiente de los Andes. La vida en tierras áridas y semiáridas. CIZA. Lima.

FALCON, MARTINEZ Y TREJO

2005 La huayllaquepa de Punkurí. Museo Nacional de Arqueología, Antropología e Historia del Perú. Revista Anales del Museo de América 13. Pags. 53-74.

FRANCO, Julio

1961 Música y Arqueología. Editorial Eterna, Lima-Perú.

GERARD A., Arnaud

1999 Acústica de las siringas andinas de uso actual en Bolivia. Informe de investigación. Universidad Autónoma Tomas Frías. Potosí, Bolivia.

GERARD A., Arnaud

2004 Interpretación acústica del ayarachi lítico "Yura" de los Museos Charca. En: Jornadas Arqueológicas. Primera Versión. Sucre, Bolivia. Universidad San Francisco Xavier de Chuquisaca.

GERARD A., Arnaud

2009 Sonidos “ondulantes” en silbatos dobles arqueológicos: ¿Una estética ancestral reiterativa? Revista Española de Antropología Americana, vol. 39, N 1 . España.

2013 Sonido tara en pifilcas arqueológicas provenientes de Potosí. En Arqueo/antropológicas, Revista de la Universidad Mayor de San Andrés. Año 3 número 3. Cochabamba, Bolivia.

IZIKOWITZ, Karl Gustav

1934 Musical and Other Sound Instruments of the South American Indians, a Comparative Ethnographical Study. Göteberg, Elanders, boktr.

\section{LANGEVIN, André}

1992 Las zampoñas de conjunto de kantu y el debate sobre la función de la segunda hilera de tubos: datos etnográficos y análisis semiótico. En, Revista Andina, Año 10, №2. Cusco.

MANSILLA V., Carlos

2009 El artefacto sonoro más antiguo del Perú: aclaración de un dato histórico. Revista Española de Antropología Americana vol. 39, № 1.

PÉREZ DE ARCE, José

1993 El Siku. En Revista Andina Nº 22. Cusco.

1996 Polifonía en fiestas rituales de Chile central. Revista Musical Chilena. Facultad de Artes, Universidad de Chile. Instituto de Extensión Musical. En, http://www.claridad.uchile.cl/ 
index.php/RMCH/article/viewFile/13834/14113

2004 “Análisis de las cualidades sonoras de las botellas silbadoras prehispánicas de los Andes". Boletín del Museo Chileno de Arte Precolombino, № 09.

SÁNCHEZ H., Carlos

2012 Orígenes y evidencias de las primeras flautas de Pan en el Perú. En, Boletín Haylli № 19, Julio. Centro Universitario de Folklore. UNMSM. Lima.

SHADY S., Ruth

2008 Los Valores sociales y culturales de Caral-supe, la civilización más Antigua del Perú y América y su rol en el desarrollo integral y sostenible. INC. Lima.

SHIBATA Koichiro

2008 El sitio de Cerro Blanco de Nepeña dentro de la dinámica interactiva del Periodo Formativo. Boletín de Arqueología PUCP / N. 12 / Pags, 287-315.

TELLO, Julio C. y Toribio MEJÍA XESSPE

1979 Paracas: Cavernas y Necrópolis II Parte. UNMSM. Lima.

TELLO, Julio C.

1999 Cuadernos de Investigación del Archivo Tello N 01, 02 y 03. Museo de Arqueología y Antropología, UNMSM. Lima.

URIBE T., Eloy

2007 Precisiones en torno al siku. En, todo Siku/ri, estudios en torno al siku y al sikuri. Folklore: Arte, cultura y sociedad. Revista del CUF-UNMSM. Año 1. $\mathrm{N}^{\circ} 1$. Lima.

VALENCIA CH., Américo

1989 El siku o zampoña. Perspectivas de un legado de un legado musical preincaico y sus aplicaciones en su desarrollo de la música peruana. CIDEMP. Artex Editores. Lima.

VARELA DE LA VEGA, Juan

1981 Anotaciones históricas sobre las flautas de Pan. En, Revista de Folklore tomo 01-A, N 5. España. 